ANADOLU, J. of AARI

ISSN: $1300-0225$ (Print)

E-ISSN: 2667-6087 (Online)

2021, 31 (1): 100-125

DOI: $10.18615 /$ anadolu.950153

\title{
Fenik Yaylası (Yayladağı/Hatay) ve Çevresinin Bitki Sosyolojisi ve Ekolojisi
}

\author{
Erdinç OĞUR ${ }^{1^{*}}$ Hayrettin OCAKVERD $\dot{I}^{2}$ \\ ${ }^{1}$ Ege Tarımsal Araştırmalar Enstitüsü Müdürlüğ̈̈, Menemen-İzmir/TURKEY \\ ${ }^{2}$ Mustafa Kemal Ünivesitesi Fen-Edebiyat Fakültesi Antakya-Hatay/TURKEY \\ ${ }^{1}$ https://orcid.org/0000-0002-4496-2995 \\ * Corresponding author (Sorumlu yazar): erdincogur@gmail.com \\ Received (Geliş tarihi): 01.02.2021Ａccepted (Kabul tarihi): 20.02.2021
}

ÖZ: Araştırma alanı olan Fenik Yaylası coğrafik olarak Doğu Akdeniz'in Amanoslar dă̆ kuşă̆ında, Samandă̆ ve Yayladağı ilçelerinin sınırları içerisinde yer alır. Fenik Yaylası, batısı Akdeniz, güneyi Yeditepe, kuzeyi Karaköse ve Yeşiltepe ile çevrili yaklaşık $61 \mathrm{~km}^{2}$ 'lik bir alandır. Fenik Yaylası'nın bitki sosyolojisi ve vejetasyon ekolojisini kapsayan bu çalışma, alanın biyolojik çeşitliliği, ekosistem çeşitliliği ve genetik kaynakların belirlenmesi, korunması ve sürdürülebilir yönetimini sağlamak amacıyla gerçekleştirilmiştir. Yapılan çalışmalar sonucunda, arazi klasik Braun-Blanquet (1932) metoduna göre analiz edilerek çalışma alanında maki vejetasyonu tipine ait 7 bitki birliği belirlendi. Üst sintaksonomik kategori değerlendirmesinde 6 tane birlik Quercion calliprini Zohary (1962) alyansl (Cisto-Quercetum cocciferae, Gynandrio-Quercetum cocciferae, MyrtoQuercetum cocciferae, Andropogo-Quercetum cocciferae, Genisto-Spartietum juncei, Myrto-Ericetum manupuliflorae), bir tane birlik Ptosimopappo-Quercion Quézel, Barbero at Akman (1978) alyansinda (Lauro-Arbutetum andrachne) değerlendirilirken tüm birlikler Quercetalia ilicis Braun-Blanquet (1947) ordosu ve Quercetea ilicis Braun-Blanquet (1947) sınıfinda değerlendirilmiştir. Birlikler sintaksonomik kategorilerin belirlenmesinin yanı sıra bitki-iklim-toprak arasındaki ilişkiler de ekolojik olarak değerlendirilmiştir. Günümüzde hızla artan insan nüfusu, çalışma alanımızda da etkisini göstermekte ve doğal bitki örtüsü üzerindeki tahribatı arttırmaktadır. Fenik yaylası ve çevresinde, en büyük tehdit olarak alanların tarım arazilerine dönüşürrülmesi bunun yanı sıra hayvan otlatılması, aşırı bitki kesimi ve yapılaşma gibi insan kaynaklı olumsuz etkiler belirlenmiştir.

Anahtar kelimeler: Hatay, Fenik Yaylast, vejetasyon, bitki sosyolojisi, ekoloji.

\section{Plant Sociology and Ecology of Fenik Plateau (Yayladă̆ı / Hatay) and its Environment}

ABSTRACT: Fenik Plateau, the study area, is located on Amanos Mountain Range within the borders of Samanda $\breve{g}$ and Yayladağ listricts. Fenik Plateau is about $61 \mathrm{~km}^{2}$ wide surrounded by Mediterranean in the west, Yeditepe in the south, Karaköse and Yeşiltepe in the north. This study includes plant sociology and vegetation ecology of Fenik Plateau in order to specify the plant biological diversity, ecosystem diversity and genetic resources of the area and than to recommend the sustainable management practises to be applied in the area. As a result of field studies, according to classical Braun-Blanquet (1932) method, totally 7 maquis plant associations were determined. The following upper category 6 of the associations were evaluated as Quercion calliprini Zohary (1962) alliance (Cisto-Quercetum cocciferae, Gynandrio-Quercetum cocciferae, Myrto-Quercetum cocciferae, Andropogo-Quercetum cocciferae, Genisto-Spartietum juncei, Myrto-Ericetum manupuliflorae) and one of the unions was evaluated as Ptosimopappo-Quercion Quézel, Barbero at Akman (1978) alliance (Lauro-Arbutetum andrachne) while all the associations were evaluated as a part of the Quercetalia ilicis Braun-Blanquet (1947) ordo and Quercetea ilicis Braun-Blanquet (1947) in class category. In addition to determining the syntaxonomic categories of the associations, the relationship between the plant, climate and soil was evaluated as well. Nowadays, rapidly growing population shows its effects on our study field and increases the damage on natural vegetation. On Fenik Plateau and its surrounding, converting the land into a farmland is the biggest threat; besides this, excessive grazing animals, cutting plants and over constructing are determined as the negative effects caused by people.

Keywords: Hatay, Fenik Plateau, vegetation, plant sosyology, ecology. 


\section{GíRiş}

İnsanlığın geleceğini güvence altına alması, doğal kaynakların araştırılması, korunması ve artan gereksinimlerine alternatif enerji kaynakları geliştirmesine bağlıdır. Bu kaynaklar içerisinde özel yeri olan vejetasyon ekolojisinin önemi tartışılmazdır. $\mathrm{Bu}$ nedenle bitkilerle çevresi arasındaki ilişkilerin araştırılması, bilinmesi ve uygulamaya koyulması birçok çevre sorununun çözümünde temel olacaktır. Vejetasyon, bir bölge veya geniş bir alanın ekolojik şartlarına göre yayılmış doğal bitki örtüsüdür. Genel anlamda ekolojik istekleri, ekolojik toleransları ve rekabet güçleri benzer olan bitkilerin, çeşitli faktörlerin etkileşmesi sonucu oluşturduğu sosyolojik cemiyetlerdir (Kılınç, 2004; Ocak-verdi, 1990).

Anadolu'nun coğrafik konumu, iklimi, jeolojisi, toprak ve su kaynakları gibi ekolojik değerleri çeşitlilik göstermektedir. Avrupa, Afrika ve Asya kıtaları arasında bir köprü durumunda ve göç yolu üzerinde olması, çok kısa mesafelerde farklılık gösteren jeolojik ve jeomorfolojik çeşitlilik, buna bağlı olarak ortaya çıkan mikroklimalar, üç fitocoğrafik bölgenin (Avrupa-Sibirya, Akdeniz, İran-Turan) kesiştiği yerde bulunması, buzul döneminde birçok canlıya sığınak olması ve pek çok bitkinin makro-mikro gen merkezi olması gibi eşsiz özellikler ülkemizi çok zengin bir flora ve farklı vejetasyon tiplerine sahip olmasina olanak tanımıştır (Demirsoy, 1996; Karagöz ve ark., 2010).

Türkiye, bitki zenginliği açısından dünyada kıta özelliği gösteren nadir ülkelerden biridir. Avrupa Kıtasında 12.000 civarında çiçekli bitki türü yetiştiği bilinirken ülkemizde bu sayı 10.000'in üzerinde olup bunların 3000 'den fazlasi da endemiktir (Ekim, 2002). Türk bilim insanlarının Türkiye florasını resimli ve Türkçe yazmasına başlamasıyla beraber Türkiye Bitkileri Listesi (Güner ve ark., 2012) kitabı ile o y1la kadar tüm literatürde var olan ülkemiz florasina ait damarlı bitkiler derlenmiş, geçerli taksonlar ve sinonimler saptanmıştır. Bu verilere göre Türkiye florası;

- 167 familya

- 1321 cins
- 10.036 tür

- 11.707 damarlı bitki taksonu (alttür, varyete, hibrit) içermektedir ve bu taksonların 3649'u (\%31,82) endemiktir (Güner ve ark., 2012).

Hatay İli, Türkiye'nin güneyinde, Akdeniz Bölgesi'nin doğu ucunda yer alır. Sulak alanları, kıyı kumulları, ovaları, makilik ve ormanlık alanlarıyla yüksek biyoçeşitlilik gösteren bir bölgedir. Toroslar'ın en doğu ucunu oluşturan İskenderun Körfezi'nin hemen doğusunda yükselen Amanos Dağları, ihtiva ettiği 251'i endemik 1580 bitki türü ile çok zengin bir habitat oluşturmaktadır. Türkiye'de tür çeşitliliği açısından en zengin doğa alanıdır. Bu taksonlar kıyıdan itibaren üç kuşak halinde tanımlanabilir; kıyılarda Akdeniz bitki örtüsü olan "maki", yukarılara çıkıldıkça Akdeniz ve Karadeniz bitki örtüsü özelliklerine sahip "ormanlar" ve orman üst sınırı üzerindeki "yüksek dağ bozkırı" bitki örtüsüdür. Dağın bitki örtüsünü oluşturan türlerin \% 65'i Akdeniz, \% 19'u Avrupa Sibirya ve \% 2,5'i İran-Turan elementlerine ait türlerden meydana gelmektedir (Zohary, 1973; Akman, 1973a; Akman, 1973b; Y1lmaz, 1996; Byfield ve ark., 2005; Güzelmansur ve ark., 2013; Ege, 2014).

Ülkemizin zengin biyoçeşitlilik ve genetik kaynakları, başta yabancı araştırıcılar olmak üzere çok sayıda bilim insanının dikkatini çekmiş ve yaptıkları çalışmalarla ülkemizin flora ve vejetasyonunu tanımlamaya çalışmışlardır. Flora ve vejetasyonu zengin olan Anadolu'da son y1llarda Ege, Karadeniz, Orta Anadolu ve Güney Batı Anadolu'da ayrıntılı çalışmalar yapılmış ve bu bölgelerdeki fitososyolojik birimlerin ortaya koyulmasında hayli yol alınmıştır. Ancak Güney Anadolu'nun Doğu Akdeniz Bölgesi'nde özellikle vejetasyon konusunda sınırlı sayıda çalışma yapılmıştır. Hatay ili sınırlarında bulunan Fenik Yaylası'nın araştırma alanı olarak seçilmesinin ilk nedeni, bölge vejetasyonundaki çalışma eksikliğini kısmen de olsa giderebilmektir. Ayrica flora ve vejetasyon yönünden çok zengin olan Doğu Akdeniz Bölgesi'nin bu kesimlerinde daha önce bitki sosyolojisi ve ekolojisi yönünden araştırma yapılmaması, birden fazla mikroklima alanı olan vadi içermesi, buraya has bitki birliklerini içeren 
farklı ekosistemler oluşturması ve insan kaynaklı tahribatın hızla sürmesi Fenik Yaylası'nın çalışma alanı olarak seçilmesinin diğer nedenleridir.

\section{MATERYAL ve METOT}

Çalışmanın materyalini, Hatay ili Yayladağı ilçesi sınırlarındaki Fenik Yaylası ve çevresinde bulunan bitki örtüsü oluşturmaktadır. Arazi çalışmaları 2004-2007 yılları arasında yapılmıştır.

\section{Araştırma alanının tanımı ve coğrafik durumu}

Hatay ili Yayladağı ilçesi sınırlarındaki Fenik Yaylası ve çevresinin sınırı; batıda Akdeniz, kuzey-batıda Meydan Köyü, kuzeyde Karaköse, güneyde Yeditepe ve doğuda Yeșiltepe yerleșim alanları ile çevrelenmiştir. Coğrafik olarak $36^{0} 00^{\prime}$ $395^{\prime \prime}-35^{0} 59^{\prime} 365^{\prime \prime}$ kuzey enlemleri ile $36^{0} 00^{\prime} 324^{\prime \prime}$ $35^{\circ} 58^{\prime} 801^{\prime \prime}$ doğu boylamları aralığında ve Doğu Akdeniz Bölgesi'nin güney ucunda bulunmaktadır (Şekil 1).

Fenik Yaylası Doğu Akdeniz'de Amanoslar Dağ Kuşağında, Samandağ ve Yayladağı sınırları arasında $61 \mathrm{~km}^{2}$ 'lik engebeli ve dağlik bir arazi yapısına sahiptir. P.H. Davis'in Grid sistemine göre Fenik Yaylası'nın çok küçük bölümü C5, geri kalan bölümü C6 karesindedir.
Araştırma alanı Mezozoik (alt ve üst kretase), Tersiyer (üst paleosen ve orta eosen) oluşukları ile temsil edilmiş, ayrıca az miktarda Kuarterner sedimanları da vardır. Plütonizma ile ilgili olarak ofiolitler bölgede geniş alanlar işgal etmektedir (Atalay, 1987; Tamer, 1974; Y1lmaz ve ark., 1984).

\section{Araștırma alanının iklimi}

İklim, yeryüzündeki tüm canlı ve cansız varlıkların yayılışına ve yaşamına etki eden en önemli faktördür. $\mathrm{Bu}$ nedenle iklimin sabit niş kullanan bitkiler için ayrı bir önemi vardır. Bitkilerin yayılıșları ekolojik isteklerine, adaptasyonları da ekolojik toleranslarına bağlı olduğundan her bitki türü iklim elemanlarının ekstrem değerleri arasında yayılabilir. İklim, bitki birliklerine uygun bir ekolojik ortam hazırlamakla kalmaz hangi tür organizmalarla yaşayacaklarını ve bölgedeki ekolojik üretimlerini de belirler. $\mathrm{Bu}$ yüzden araştırma alanlarında iklim verilerinin belirlenmesi araştırmanın en önemli ekolojik yönünü oluşturmaktadır. İklim kavramı içerisinde dikkate alınması gereken en önemli faktörler sıcaklık, yağıș, nem ve rüzgârdır. Araștırma alanı, tipik Akdeniz iklim kuşağı içerisinde yer alır. İklim bilgileri, Meteoroloji Genel Müdürlüğü'nün Samandağ Meteoroloji İstasyonu'nda yapılan 19752004 yılları arasındaki verilerine göre hazırlanmıştır (Şekil 2).

\section{Araștırma alanının kısa jeolojisi}

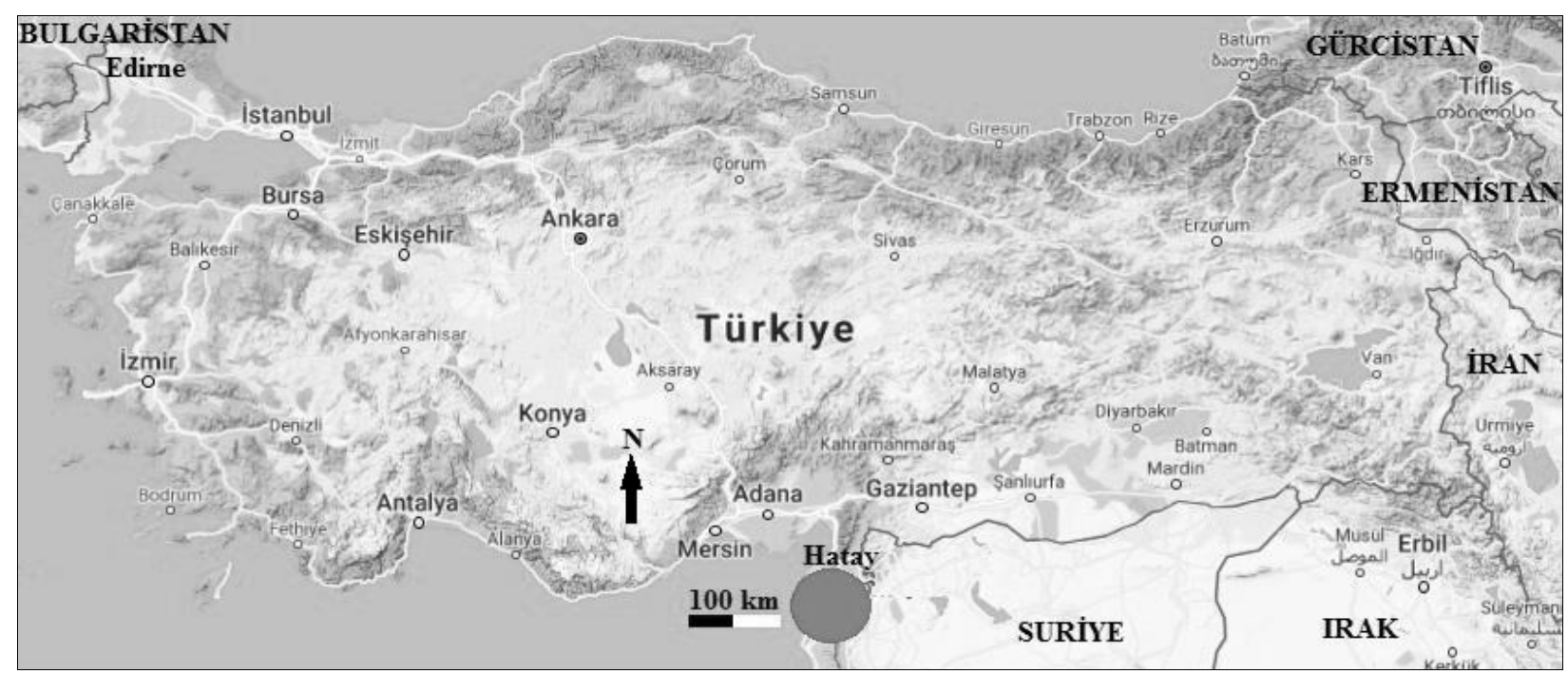

Şekil 1. Araştırma alanının haritası.

Figure 1. Map of the research area. 


\section{Yağışlar}

Bölgenin yıllık yağış miktarı 895,2 mm'dir. Aylık en yüksek yağış ortalaması $142 \mathrm{~mm}$ ile Aralık ayında, en düşük ise $7,4 \mathrm{~mm}$ ile Temmuz ve Ağustos aylarındadır. En yağışlı mevsim sırasıyla Kiş (Aralık 142 mm, Ocak 140,6 mm, Şubat 119,9 $\mathrm{mm}$ ), Sonbahar (Eylül 36,2 mm, Ekim 97,1 mm, Kasım 110,3 mm), İlkbahar (Mart 109,7 mm, Nisan 65,9 mm, Mayıs $45 \mathrm{~mm}$.) ve Yaz (Haziran 13,7 mm, Temmuz 7,4 mm, Ağustos 7,4 mm) dır. $\mathrm{Bu}$ verilere göre bölgenin yağış rejimi karakteristik doğu Akdeniz tipi olup Kış, Sonbahar, İlkbahar, Yaz (K.S.İ.Y) şeklindedir.

\section{Sicaklık}

Bölgede ortalama yıllık sıcakl1k $19{ }^{\circ} \mathrm{C}$ 'dir. Burada aylık ortalama sıcaklık olarak en yüksek $27,8^{\circ} \mathrm{C}$ ile Ağustos ayında, en düşük de $9,9{ }^{\circ} \mathrm{C}$ ile Ocak ayındadır. En sicak ay Ağustos olup maksimum sicaklık ortalamas $30,5{ }^{\circ} \mathrm{C}$, en soğuk ay ise Ocak olup minimum sicaklık ortalamas $6,5^{\circ} \mathrm{C}$ dir.

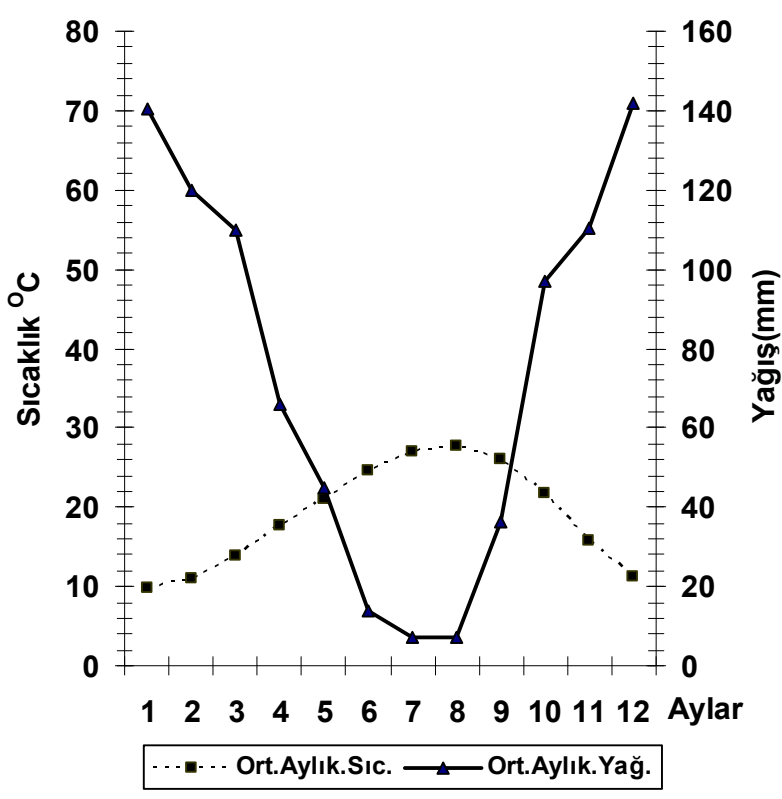

Şekil 2. Araștırma alanının iklim diyagramı (1975-2004). Figure 2. Climate diagram of the research area (1975-2004).

\section{Nispi nem}

Yıllık bağıl nem miktarı ortalaması \%75'tir. Nisan, Mayıs, Haziran, Temmuz, Ağustos ve Eylül yıllık ortalamanın üzerinde olan aylardır. En yüksek aylık ortalama bağıl nem miktarı \%81 ile Haziran ve Temmuz aylarında iken, en düşük aylık ortalama bağıl nem miktarı \%66 ile Kasım ayına aittir (Anonymous, 2004).

\section{Rüzgâr}

Akdeniz bölgesinde rüzgâr genellikle kışın karadan denize, yazın ise denizden karaya doğru eser (Uslu 1974). Ana ve ara yönlere ait rüzgâr diyagramına bakıldığında, rüzgârın en fazla Güneybatı yönünde estiği görülür. Aylara göre en hızlı rüzgâr $31,4 \mathrm{~m} / \mathrm{s}$ hızla Ekim, en yavaş ise $18,4 \mathrm{~m} / \mathrm{s}$ ile Haziran aylarına aittir (Anonymous, 2004).

\section{Survey-envanter çalışmaları}

Araştırma alanının vejetasyonuna ait bilgiler, vejetasyonun optimum geliştiği dönemlerde yapılan periyodik survey-envanter çalışmaları belirlenmiştir. Arazi çalıșmaları esnasında bitki örnekleri, teşhise imkân tanıyan yapraklı ve çiçekli kısımlarıyla toplanmış, habitat özellikleri, bitki yoğunluğu, yükselti, tarih ve lokaliteler arazi defterine not edilmiştir. Toplanan bitki örnekleri yayılıș alanlarında gözlemlenmiş, bitkilerin yayılıș alanları, ekolojik özellikleri ve türler üzerindeki olumsuz etkiler belirlenmiştir.

Bitkilerle çevre arasındaki ilişkileri belirlemek için vejetasyonu habitat ve floristik kompozisyon bakımından temsil edecek, bitki örtüsü bakımından homojen olduğu gözlenen alanlardan örnek parseller alınmıştır. Vejetasyon araştırmaları sırasında örnek parsel yapılırken araştırmaların temeli durumundaki ekolojik verilere dayalı Braun-Blanquet (1932) metodu esas alınmıştır.

Çalışma alanındaki bitki birliklerini temsil edecek örnek alan büyüklügü sosyolojik ilişkilere dayanan en küçük örneklik alan (minimal area) metodu kullanılarak yapılmıştır (Braun-Blanquet 1932). Birliklerin tümü maki vejetasyonu karakterli olduğundan örnek alan büyüklüğü hepsinde $400 \mathrm{~m}^{2}$ olarak belirlenmiştir. Arazinin morfolojik yapısının durumu, bitki örtüsünün homojenliği ve yayılma genişliğine göre birliklerin örnek parsel sayıları farkl111k göstermiştir.

Araştırma alanından alınan örnek parsellerin değerlendirilmesi sonucu ekolojik ve floristik 
yönden belirgin benzerlik taşıyan kesimler bitki birliği olarak tanımlanmıştır. Tanımlanan bitki birliklerine ait vejetasyon tabloları da BraunBlanquet (1932) metodu esas alınarak yapılmıştır. Tablolarda belirlenmiş bitki birliklerini temsil eden floristik kompozisyonu oluşturan türlerin sintaksonomik kategorilere dağılışını belirlemek için Akman ve ark. (1978; 1979a; 1979b), Ocakverdi (1990), Akman (1995), Çakan (1997), Duman ve Aytaç (1994), Düzenli (1976), Quézel ve ark. (1978), Quézel ve ark. (1980), Quézel ve ark. (1992), Uslu (1977), Vural ve ark. (1994; 1999), Yolcu (2005) ve Yurdakulol (1973)'nun çalışmalarından yararlanılmıştır.

\section{Botanik sınıflandırma}

Arazi çalışmaları esnasında bitki örnekleri tüm tanımlayıcı parçalarıyla toplanmış, herbaryum tekniklerine uygun olarak kurutulmuş ve herbaryum örneği haline getirilmiștir (Seçmen ve ark., 2008; Tan ve ark., 2001). Herbaryum örnekleri önce familya ve cins düzeyinde teşhis ve tasnif edildikten sonra tür ve tür altı kategorilerinin teşhisi yapılmıştır (Davis, 1965-1985; Davis ve ark., 1988; Güner ve ark., 2000).

\section{Alanın büyük toprak grupları ve toprak analizleri}

Araştırma alanını içine alan Amanos Dağları'nda, toprak grupları Akman (1973a)'a göre marn anakaya üzerinde erozyon topraklar, kahverengi kalkerli topraklar, kahverengi yıkanmış topraklar, kahverengi orman toprakları ve kırmızı akdeniz toprakları olmak üzere 5 toprak tipi tanımlamıştır.

Toprak, içerdiği besin maddeleri ve bu maddelerin yeniden üretilmesini sağlayan madde döngüsü sayesinde üzerinde ve içerisindeki canlı ve cansız varlıklarla birlikte başlı başına bir ekosistemdir üzerinde ve içinde yaşayan canlıları besleyen ve barındıran bir ortamdır. Bu ekosistemler, çevrenin diğer faktörleriyle birlikte uyum ve denge sonucunda oluştuğu bilinmektedir. Toprak, jeolojik yapının parçalanmasıyla açığa çıkan çeşitli ölçülerdeki kum, kil ve silt ile canlı organik artıklarının ayrıştırılmasıyla oluşan organik maddelerin, hava ve su gibi atmosferik üyelerin karışımından oluşur. Her toprak çeşidinin özel yapısı ve bileşimi ile fiziksel ve biyolojik özellikleri vardır. Oluşumu binlerce yıl gerektiren toprağın özelliklerini yansıtan faktörlerin başında iklim, mineral madde ve üzerinde yaşayan canlılar gelir (Billings, 1968).

Araștırma alanında belirlenen bitki birliklerinin yayıldıkları topraklar hakkında bilgiler her birlikten alınan örneklerin analizi sonucu elde edilmiştir (Çizelge 1). Örnekler önce Mustafa Kemal Üniversitesi Ziraat Fakültesi Toprak Anabilim Dalı laboratuvarlarında açık havada kurutulup 2 mm'lik eleklerden geçirildikten sonra kimyasal ve fiziksel analizleri yapılmıştır. Analizlerde kullanılan yöntemler aşağ 1 da özetlenmiştir.

Tekstür; Bouyoucos-Hidrometre metoduyla toprak örneklerine ait (\% silt, \% kil ve \% kum) bünye özellikleri belirlenmiştir (Bouyoucus, 1962).

Su ile doygunluk; 100 gr. Hava kurusu toprağın sature hale gelinceye kadar ilave edilen saf su miktarının yüzde ifadesidir (Richards, 1954).

pH; Cam ve kalomel elektrotlu Beckman pH metresi kullanıldı. pH ölçümleri saf su ile hazırlanmış ve 24 saat bekletilmiş saturasyon çamurlarında ölçülmüştür (Richards, 1954).

Kireç $\left(\mathrm{CaCO}_{3}\right)$; Scheibler kalsimetresindeki $\mathrm{CO}_{2}$ basıncına göre sonuçlar $\mathrm{CaCO}_{3}$ olarak hesaplanmıştır (Allison, 1965).

Organik madde (\%); Walkley-Black yaş yakma sistemine göre demir sülfat titrasyonu ile yapılmıştır (Allison, 1965).

Total Azot (\%); Kjeldal metoduna göre belirlendi (Bremner, 1965). 
Çizelge 1. Araştırma alanındaki bitki birliklerinden alınan toprak örneklerinin analiz sonuçları.

Table 1. Analysis results of the soil sample taken from the plant associations in the study field.

\begin{tabular}{|c|c|c|c|c|c|c|c|c|}
\hline $\begin{array}{l}\text { Örnek no } \\
\text { (Sample } \\
\text { no) }\end{array}$ & $\begin{array}{c}\text { Toplam organik } \\
\text { madde } \\
\text { (Total organic } \\
\text { matter) }\end{array}$ & $\begin{array}{l}\text { Toplam } \\
\text { azot } \\
\text { (Total } \\
\text { nitrogen) }\end{array}$ & $\mathrm{pH}$ & $\begin{array}{c}\text { Tarla } \\
\text { kapasitesi } \\
\text { (Field } \\
\text { capacity) (\%) }\end{array}$ & $\begin{array}{c}\text { Kireç } \\
(\text { Lime }) \\
\left(\mathrm{CaCO}_{3}\right)\end{array}$ & $\begin{array}{c}\text { İletkenlik } \\
\text { (Conductivity) } \\
(\mathrm{mS} / \mathrm{cm})\end{array}$ & $\begin{array}{l}\text { Tekstür } \\
\text { (Texture) }\end{array}$ & $\begin{array}{c}\text { Bitki birlikleri } \\
\text { (Plant } \\
\text { association) }\end{array}$ \\
\hline $1 \mathrm{a}$ & 5,23 & 0,26 & 6,97 & 38 & 24,5 & 1,34 & $\begin{array}{l}\text { Killi-Tın } \\
\text { Clay-Loam }\end{array}$ & \multirow{2}{*}{$\begin{array}{l}\text { Cisto- } \\
\text { Quercetum } \\
\text { cocciferae }\end{array}$} \\
\hline $1 b$ & 5,38 & 0,27 & 6,86 & 42 & 23,6 & 1,48 & $\begin{array}{l}\text { Killi-Tın } \\
\text { Clay-Loam }\end{array}$ & \\
\hline $2 \mathrm{a}$ & 2,8 & 0,14 & 7,14 & 28 & 29,1 & 1,77 & $\begin{array}{l}\text { Kumlu-Kil } \\
\text { Sandy-Clay }\end{array}$ & \multirow{2}{*}{$\begin{array}{l}\text { Gynandrio- } \\
\text { - Quercetum } \\
\text { cocciferae }\end{array}$} \\
\hline $2 b$ & 3,5 & 0,17 & 7,09 & 30 & 26,2 & 1,45 & $\begin{array}{l}\text { Kumlu-Kil } \\
\text { Sandy-Clay }\end{array}$ & \\
\hline $3 a$ & 5,3 & 0,27 & 6,99 & 35 & 12,2 & 1,17 & $\begin{array}{l}\text { Killi-Tın } \\
\text { Clay-Loam }\end{array}$ & \multirow{2}{*}{$\begin{array}{l}\text { Mryto- } \\
\text { - Quercetum } \\
\text { cocciferae }\end{array}$} \\
\hline $3 b$ & 6,4 & 0,32 & 6,84 & 44 & 9,4 & 1,19 & $\begin{array}{l}\text { Killi-Tın } \\
\text { Clay-Loam }\end{array}$ & \\
\hline $4 a$ & 2,3 & 0,12 & 7,30 & 32 & 47,1 & 1,92 & $\begin{array}{l}\text { Kil } \\
\text { Clay }\end{array}$ & \multirow{2}{*}{$\begin{array}{l}\text { Andropogo- } \\
\text { - Quercetum } \\
\text { cocciferae }\end{array}$} \\
\hline $4 b$ & 2,7 & 0,14 & 7,31 & 34 & 45,9 & 1,71 & $\begin{array}{l}\text { Kil } \\
\text { Clay }\end{array}$ & \\
\hline $5 a$ & 8,4 & 0,42 & 6,79 & 52 & 4,4 & 1,34 & $\begin{array}{l}\text { Killi-Tın } \\
\text { Clay-Loam }\end{array}$ & \multirow{2}{*}{$\begin{array}{l}\text { Lauro- } \\
\text { - Arbutetum } \\
\text { andrachne }\end{array}$} \\
\hline $5 b$ & 11,8 & 0,55 & 6,77 & 61 & 3,1 & 1,26 & $\begin{array}{l}\text { Tin } \\
\text { Loam }\end{array}$ & \\
\hline $6 a$ & 7,6 & 0,38 & 6,89 & 48 & 7,6 & 1,38 & $\begin{array}{l}\text { Killi-Tın } \\
\text { Clayey-Loam }\end{array}$ & \multirow{2}{*}{$\begin{array}{l}\text { Genisto - } \\
\text { - Spartietum } \\
\text { juncei }\end{array}$} \\
\hline $6 b$ & 6,8 & 0,34 & 6,92 & 40 & 9,2 & 1,42 & $\begin{array}{l}\text { Killi-Tın } \\
\text { Clay-Loam }\end{array}$ & \\
\hline $7 \mathrm{a}$ & 13,2 & 0,65 & 6,72 & 65 & 2,1 & 1,29 & $\begin{array}{l}\text { Tin } \\
\text { Loam }\end{array}$ & \multirow{2}{*}{$\begin{array}{l}\text { Myrto- } \\
\text {-Ericetum } \\
\text { manupuliflorae }\end{array}$} \\
\hline $7 b$ & 10,4 & 0,52 & 6,87 & 58 & 3,2 & 1,35 & $\begin{array}{l}\text { Killi-Tın } \\
\text { Clay-Loam }\end{array}$ & \\
\hline
\end{tabular}

\section{BULGULAR ve TARTIȘMA}

Bölgede yapılan survey ve envanter çalışmalarıyla Fenik Yaylası'nda farklı iklim, toprak, anakaya, bakı ve insan faaliyetleri sonucu çeşitli bitki birliklerinin yayıldı̆̆ belirlenmiştir. Fenik Yaylası'nın vejetasyonu, batıdaki deniz seviyesinden doğuya doğru yükselen ve en yüksek noktası olan Aydınbahçe'ye (650 m.) kadar maki vejetasyonundan oluşan yatay bir tabakalaşma gösterir. Makinin hâkim türü Quercus coccifera olup sahildeki 35 m'den itibaren örtüş dereceleri değişen çalılıklar şeklinde yayılmıştır. Arazinin engebeli olması ve çeşitli vadilerin varlığı, burada farklı türlerin hâkimiyetini belirlemede en önemli etken olmuştur. $\mathrm{Bu}$ çalışmada araştırma alanı içerisinde 7 bitki birliğ tanımlanmıştır.

Alyans: Quercion calliprini Zohary (1962)

Ordo : Quercetalia ilicis Braun-Blanquet (1947)

Sinıf : Quercetea ilicis Braun-Blanquet (1947)

1. Cisto-Quercetum cocciferae birliği

2. Gynandrio-Quercetum cocciferae birliği

3. Myrto-Quercetum cocciferae birliğ $i$

4. Andropogo-Quercetum cocciferae birliği

5. Genisto-Spartietum juncei birliği 


\section{Myrto- Ericetum manupuliflorae birliği}

Alyans: Ptosimopappo-Quercion Quézel, Barbéro \& Akman (1978)

Ordo : Quercetalia ilicis Braun-Blanquet (1947)

Sinıf : Quercetea ilicis Braun-Blanquet (1947)

7. Lauro-Arbutetum andrachne birliğ $i$

\section{Araştırma alanının vejetasyon ekolojisi}

\section{Cisto-Quercetum cocciferae birliği}

Araştırma alanında en yaygın bitki olan ve ancak $130 \mathrm{~cm}$. kadar boylanabilen Quercus coccifera L. bitkisi birliğin de dominant türüdür. Habitatın ekolojik koşullarına uygun olarak Cistus salviifolius L., Rhamnus alaternus L, Allium subhirsutum L. ve Scorzonera kotschyi Boiss. birlik içerisinde yoğun tekerrür ettiği için karakter tür olarak seçilmiştir (Çizelge 2.).
GPS koordinatları N. $35^{\circ} 59^{\prime} 589^{\prime \prime}$ ve E. $35^{\circ} 59^{\prime}$ 920 " olan birlik araştırma alanının batıya bakan \% $30-50$ eğimli ve $130-300 \mathrm{~m}$. yüksekliklerinde yayılır. Habitat \% 10 kadar Rupikol özellik gösterse de çakıl oranı az olduğundan fazla hareketli değildir. Geniş gruplar halinde yayılan birliğin toprağ1 killi tın bünyeli, ortalama organik maddesinin \% 5,4 olmas1 hem pH'nin nötre yakınlığına hem de kireç miktarının \% 24,5 şeklinde yükselmesine imkân vermiştir. Habitat hâkim batı rüzgârından fazla etkilendiği için bitkilerde transprasyon artmıştır. $\mathrm{Bu}$ durum floristik kompozisyonun zayıflamasina ve bitkilerin de bodurlaşmasına neden olmuştur. Toplam 8 örnek parsel ile tanımlanan birlik sintaksonomik olarak Quercion calliprini Zohary (1962) alyans1, Quercetalia ilicis Braun-Blanquet (1947) ordosu ve Quercetea ilicis Braun-Blanquet (1947) sinifi içerisinde değerlendirilmiştir.

Çizelge 2. Cisto-Quercetum cocciferae Birliği.

Table 2. Cisto-Quercetum cocciferae plant association.

\begin{tabular}{|c|c|c|c|c|c|c|c|c|c|}
\hline \multicolumn{10}{|l|}{ Ö } \\
\hline Örnek parsel no (Sample parcel number) & 1 & 2 & 3 & 5 & 4 & 6 & 7 & 8 & \multirow{10}{*}{ 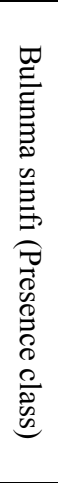 } \\
\hline Alan genişliği (Field width) $\left(\mathrm{m}^{2}\right)$ & 400 & 400 & 400 & 400 & 400 & 400 & 400 & 400 & \\
\hline Yükseklik (Height) (m) & 130 & 160 & 190 & 200 & 225 & 240 & 265 & 290 & \\
\hline Yön (Direction) ${ }^{*}$ & $\mathrm{~B} / \mathrm{W}$ & $\mathrm{B} / \mathrm{W}$ & $\mathrm{B} / \mathrm{W}$ & $\mathrm{B} / \mathrm{W}$ & $\mathrm{B} / \mathrm{W}$ & $\mathrm{B} / \mathrm{W}$ & $\mathrm{B} / \mathrm{W}$ & $\mathrm{B} / \mathrm{W}$ & \\
\hline Eğim (Slope) $\left(^{\mathrm{O}}\right)$ & 45 & 45 & 50 & 50 & 50 & 55 & 55 & 55 & \\
\hline Anakaya (Bedrock) & \multicolumn{8}{|c|}{ Kireçtaşı (Limestone) } & \\
\hline Genel örtüş (General overlap) (\%) & 95 & 80 & 90 & 85 & 85 & 80 & 85 & 85 & \\
\hline Çalı örtüş (Shrub overlap) (\%) & 90 & 75 & 80 & 80 & 80 & 80 & 80 & 85 & \\
\hline Çalı boyu (Shrub lenght) (cm) & 150 & 110 & 100 & 130 & 120 & 125 & 135 & 130 & \\
\hline Ot örtüş (Grass overlap) (\%) & 30 & 25 & 30 & 35 & 30 & 30 & 30 & 30 & \\
\hline \multicolumn{10}{|l|}{$\begin{array}{l}\text { Birliğin karakter türleri } \\
\text { (Character types of the union) }\end{array}$} \\
\hline Quercus coccifera & 34 & 34 & 33 & 34 & 33 & 33 & 34 & 34 & $\mathrm{~V}$ \\
\hline Cistus salviifolius & 22 & 22 & 22 & 22 & 12 & 22 & 12 & 22 & $\mathrm{~V}$ \\
\hline Rhamnus alaternus & 12 & 22 & 22 & 22 & +2 & 22 & +2 & 22 & $\mathrm{~V}$ \\
\hline Allium subhirsitum & +1 & +1 & +1 & +1 & +1 & +1 & +1 & +1 & V \\
\hline Scorzonera kotschyi & +1 & +1 & . & +1 & . & +1 & +1 & . & IV \\
\hline \multicolumn{10}{|l|}{$\begin{array}{l}\text { Quercion calliprini alyansının karakter türleri } \\
\text { (Character types of Quercion calliprini alliance) }\end{array}$} \\
\hline Rubia tenuifolia subsp. brachypoda & +2 & +1 & +1 & +1 & +1 & +1 & +1 & +1 & $\mathrm{~V}$ \\
\hline \multicolumn{10}{|l|}{$\begin{array}{l}\text { Qercetalia ilicis ordosunun karakter türleri } \\
\text { (Character types of the Qercetalia ilicis ordo) }\end{array}$} \\
\hline Phillyrea latifolia & . & +1 & +1 & . & +1 & +1 & +1 & +1 & IV \\
\hline Geranium purpureum & +1 & +1 & . & +1 & +1 & +1 & . & . & IV \\
\hline $\begin{array}{l}\text { Quercetea ilicis sınıfının karakter türleri } \\
\text { (Character types of the Qercetalia ilicis class) }\end{array}$ & & & & & & & & & \\
\hline
\end{tabular}


Çizelge 2. Devam

Table 2. Continued

\begin{tabular}{l} 
Cyclamen persicum \\
Pistacia terebinthus \\
Asparagus acutifolius \\
Melica eligulata \\
Myrtus communis \\
Ptosimopappo-Quercion alyansının karakter türleri \\
(Character types of Ptosimopappo-Quercion alliance) \\
\hline Astragalus schizopterus \\
Fagetali silvaticae ordosunun karakter türleri \\
(Character types of the Fagetali silvaticae ordo) \\
\hline Festuca heterophylla \\
Quercetea pubescentis sinıfinın karakter türleri \\
(Character types of the Quercetea pubescentis class)
\end{tabular}

\begin{tabular}{cccccccc|}
21 & 11 & 21 & 21 & 11 & 21 & 11 & 11 \\
+2 & 12 & 12 & 12 & 12 & 12 & 11 & 11 \\
+1 &. &. &. & +1 & +1 &. &. \\
. &. & +1 & +1 & +1 &. &. &. \\
. &. &. &. &. &. & +2 & +2
\end{tabular}

Coronilla emerus subsp. emeroides

$+1$

Cisto-Micromerietea sınıfinın karakter türleri

(Character types of the Cisto-Micromerietea class)

Cistus creticus
Micromeria myrtifolia
Psoralea bituminosa
Teucrium polium
Themeda triandra
Astragalo-Brometea sinıfinın karakter türleri
(Character types of the Astragalo-Brometea class)

Bromus tectorum
Helianthemum nummularium
Diğerleri (Others)

Genista acanthoclada

Piptatherum miliaceum

Dactylis glomerata

Lotus peregrinus var. peregrinus

Galium floribundum subsp. floribundum

Galium verum

Asperula arvensis

Ornithogalum narbonense

Allium rubellum

Minuartia mesogitana

Capsella bursa-pastoris

Callipeltis cucullaria

Carduus pycnocephalus subsp. albidus

Silene aegyptiaca subsp. aegyptiaca

Euophorbia taurinensis

Senecio vernalis

Geranium rotindifolium

Ruta chalepensis

Anagallis arvensis

\begin{tabular}{cccccccc|c}
11 & $\cdot$ & 11 & 12 & 12 & 12 & 22 & 12 & $\mathrm{~V}$ \\
+2 & +1 & +1 & +2 & +1 & +1 & $\cdot$ & +1 & $\mathrm{~V}$ \\
+1 & +1 & $\cdot$ & $\cdot$ & $\cdot$ & +1 & +1 & +1 & $\mathrm{IV}$ \\
+1 & +1 & +1 & $\cdot$ & $\cdot$ & $\cdot$ & $\cdot$ & $\cdot$ & $\mathrm{II}$ \\
$\cdot$ & +1 & +1 & $\cdot$ & +1 & $\cdot$ & $\cdot$ & $\cdot$ & $\mathrm{II}$ \\
& & & & & & & & \\
11 & 11 & 11 & 12 & 11 & 11 & 11 & 12 & $\mathrm{~V}$ \\
$\cdot$ & +1 & +1 & $\cdot$ & $\cdot$ & $\cdot$ & $\cdot$ & $\cdot$ & $\mathrm{II}$ \\
& & & & & & & & \\
22 & 12 & 12 & 12 & 22 & 22 & 12 & 22 & $\mathrm{~V}$ \\
21 & 21 & 11 & 11 & 11 & 11 & 11 & 11 & $\mathrm{~V}$ \\
11 & 11 & 11 & 12 & 11 & 11 & +2 & 11 & $\mathrm{~V}$ \\
11 & 11 & +2 & +2 & +2 & +2 & +1 & +1 & $\mathrm{~V}$ \\
+2 & 11 & +2 & 11 & +2 & +2 & 11 & 11 & $\mathrm{~V}$ \\
+2 & +2 & +2 & +2 & +1 & +1 & +1 & +1 & $\mathrm{~V}$ \\
+1 & +1 & +1 & +1 & +1 & +1 & +1 & +1 & $\mathrm{~V}$ \\
+1 & +1 & +1 & +1 & +1 & +1 & +1 & +1 & $\mathrm{~V}$ \\
+1 & +1 & +1 & +1 & +1 & +1 & +1 & +1 & $\mathrm{~V}$ \\
+1 & +1 & +1 & +1 & +1 & +1 & +1 & +1 & $\mathrm{~V}$ \\
11 & 11 & $\cdot$ & $\cdot$ & +1 & +1 & +1 & +1 & $\mathrm{IV}$ \\
+1 & +1 & +1 & +1 & +1 & +1 & $\cdot$ & $\cdot$ & $\mathrm{IV}$ \\
+1 & +1 & +1 & +1 & +1 & +1 & $\cdot$ & $\cdot$ & $\mathrm{IV}$ \\
+1 & +1 & +1 & +1 & +1 & +1 & $\cdot$ & $\cdot$ & $\mathrm{IV}$ \\
+1 & +1 & +1 & +1 & +1 & $\cdot$ & $\cdot$ & +1 & $\mathrm{IV}$ \\
+1 & $\cdot$ & +1 & +1 & +1 & $\cdot$ & +1 & +1 & $\mathrm{IV}$ \\
+1 & +1 & +1 & $\cdot$ & +1 & $\cdot$ & +1 & +1 & $\mathrm{IV}$ \\
$\cdot$ & +2 & +2 & +1 & $\cdot$ & +1 & +1 & +1 & $\mathrm{IV}$ \\
$\cdot$ & +1 & +1 & +1 & +1 & +1 & +1 & $\cdot$ & $\mathrm{IV}$
\end{tabular}


Çizelge 2. Devam

Table 2. Continued

Stipa bromoides

Lolium perenne

Linaria chalepensis

Salvia verticillata

Orobanche nana

Aegilops umbellulata

Cytinus hypocistis

Micromeria graeca

Medicago polymorpha

Thlaspi annuum

Dianthus strictus

Lamium amplexicaule

Scandix pecten-veneris

Ajuga chamaepitys

Hymenocarpus circinnatus

Catapodium rigidum

Convolvulus cantabrica

Ornithogalum sphaerocarpum

Sedum caespitosum

\section{Gynandrio-Quercetum cocciferae birliği}

Quercus coccifera L. burada da hâkim durumdadır ve Samandağ sahilinin doğu ucundaki Sabra burnundan Fenik Yaylası'na doğru $40 \mathrm{~m}$. yüksekliğe kadar yayılmıştır. Gladiolus antakiensis A.P. Hamilton lokal endemik olduğundan, Gynandris sisyrinchium (L) Parl., Leontodon crispus Vill., Cicerbita mulgedioides (Schult Bip. ex Vis. et Panc ) Beauverd birlik içerisinde yüksek tekerrürlü olduklarından karakter tür olarak seçilmiştir (Çizelge 3).

Birlik ilkbahar başlangıcından kış aylarına kadar karakeçinin otlak alanı olarak kullanılmaktadır. Ayrıca yerleşim alanına ve deniz kenarına yakın olduğundan hem piknik alanı olarak kullanılmakta hem de yakacak olarak aşırı kesim yapılmaktadır. $O$ yüzden birlik içerisinde belirgin sinüzya teşekkülü olmamış ve floristik kompozisyon zayıf

\begin{tabular}{|c|c|c|c|c|c|c|}
\hline . & +1 & +1 & +1 & +1 & +1 & +1 \\
\hline . & +1 & +1 & +1 & +1 & +1 & +1 \\
\hline+1 & +1 & +1 & +1 & . & . & . \\
\hline+1 & +1 & +1 & +1 & . & . & . \\
\hline+1 & . & +1 & . & +1 & +1 & +1 \\
\hline . & +1 & +1 & . & +1 & +1 & +1 \\
\hline+1 & +1 & . & . & . & +1 & . \\
\hline+1 & . & . & . & +1 & . & +1 \\
\hline+1 & . & +1 & +1 & . & . & . \\
\hline+1 & +1 & +1 & . & . & . & . \\
\hline+1 & . & . & +1 & +1 & . & . \\
\hline+1 & +1 & . & +1 & . & . & . \\
\hline+1 & . & . & . & . & +1 & . \\
\hline+1 & . & +1 & . & . & . & . \\
\hline+1 & . & +1 & +1 & . & . & . \\
\hline . & . & +1 & +1 & +1 & . & . \\
\hline+1 & +1 & . & . & . & . & . \\
\hline+2 & +2 & . & . & . & . & . \\
\hline . & . & +1 & +1 & . & . & $\cdot$ \\
\hline
\end{tabular}

kalmıştır. $\mathrm{Bu}$ durum \% 30 eğime rağmen orta derecede erozyona yol açtığı için organik maddesi azalan toprağın kum ve kireç miktarını arttırmış, su tutma kapasitesini düşürmüştür.

$\mathrm{Bu}$ olumsuz etkenler, bitkilerin belli bir su stresi yaşamalarına ve azami $140 \mathrm{~cm}$. boylanabilen bodur maki katının gelişmesine neden olmuştur. Ancak sicaklık ve nemin optimum özelliği makilerde büyümenin sürekliliğini sağladığ için ekosistemin tampon gücünü koruyacak prodüktiviteye imkan vermiştir. GPS koordinatları N. $36^{\circ} 00^{\prime} 245^{\prime \prime}$ ve E. $35^{\circ} 58^{\prime} 482^{\prime \prime}$ olan birlik, Nisan 2005 tarihinde yapılan 9 örnek parsel ile tanımlanmıştır. Sintaksonomik olarak da Quercion calliprini Zohary (1962) alyans1, Quercetalia ilicis Braun-Blanquet (1947) ordosu ve bunların bağlı bulunduğu Quercetea ilicis Braun-Blanquet (1947) sınıfı içerisinde değerlendirilmiştir. 
Çizelge 3. Gynandrio - Quercetum cocciferae birliği.

Table 3. Gynandrio - Quercetum cocciferae plant association.

Örnek parsel no (Sample parcel num
Alan genişliği (Field width) $\left(\mathrm{m}^{2}\right)$
Yükseklik (Height) $(\mathrm{m})$
Yön (Direction)
Eğim (Slope) $\left(^{\mathrm{O}}\right)$
Anakaya (Bedrock)
Genel örtüş (General overlap) $(\%)$
Çalı örtüş (Shrub overlap) $(\%)$
Çalı boyu (Shrub lenght) $(\mathrm{cm})$
Ot örtüş (Grass overlap) $(\%)$

$\begin{array}{lllllllll}9 & 10 & 15 & 12 & 14 & 16 & 11 & 13 & 17\end{array}$

Alan genişliği (Field width) $\left(\mathrm{m}^{2}\right)$

Yükseklik (Height) (m)

Yön (Direction)

Eğim (Slope) $\left({ }^{\circ}\right)$

Anakaya (Bedrock)

Çalı örtüş (Shrub overlap) (\%)

Ot örtüş (Grass overlap)(\%)

$\begin{array}{ccccccccc}400 & 400 & 400 & 400 & 400 & 400 & 400 & 400 & 400 \\ 35 & 35 & 55 & 45 & 50 & 60 & 40 & 50 & 60 \\ \mathrm{~B} / \mathrm{W} & \mathrm{B} / \mathrm{W} & \mathrm{B} / \mathrm{W} & \mathrm{B} / \mathrm{W} & \mathrm{B} / \mathrm{W} & \mathrm{B} / \mathrm{W} & \mathrm{B} / \mathrm{W} & \mathrm{B} / \mathrm{W} & \mathrm{B} / \mathrm{W} \\ 25 & 25 & 30 & 25 & 25 & 30 & 20 & 30 & 35 \\ 60 & 80 & 95 & 70 & 100 & 100 & 95 & 90 & 90 \\ 85 & 70 & 85 & 65 & 100 & 95 & 90 & 75 & 85 \\ 60 & 70 & 80 & 70 & 110 & 150 & 80 & 75 & 75 \\ 25 & 40 & 30 & 40 & 20 & 20 & 40 & 30 & 15\end{array}$

Birliğin karakter türleri

(Character types of the union)

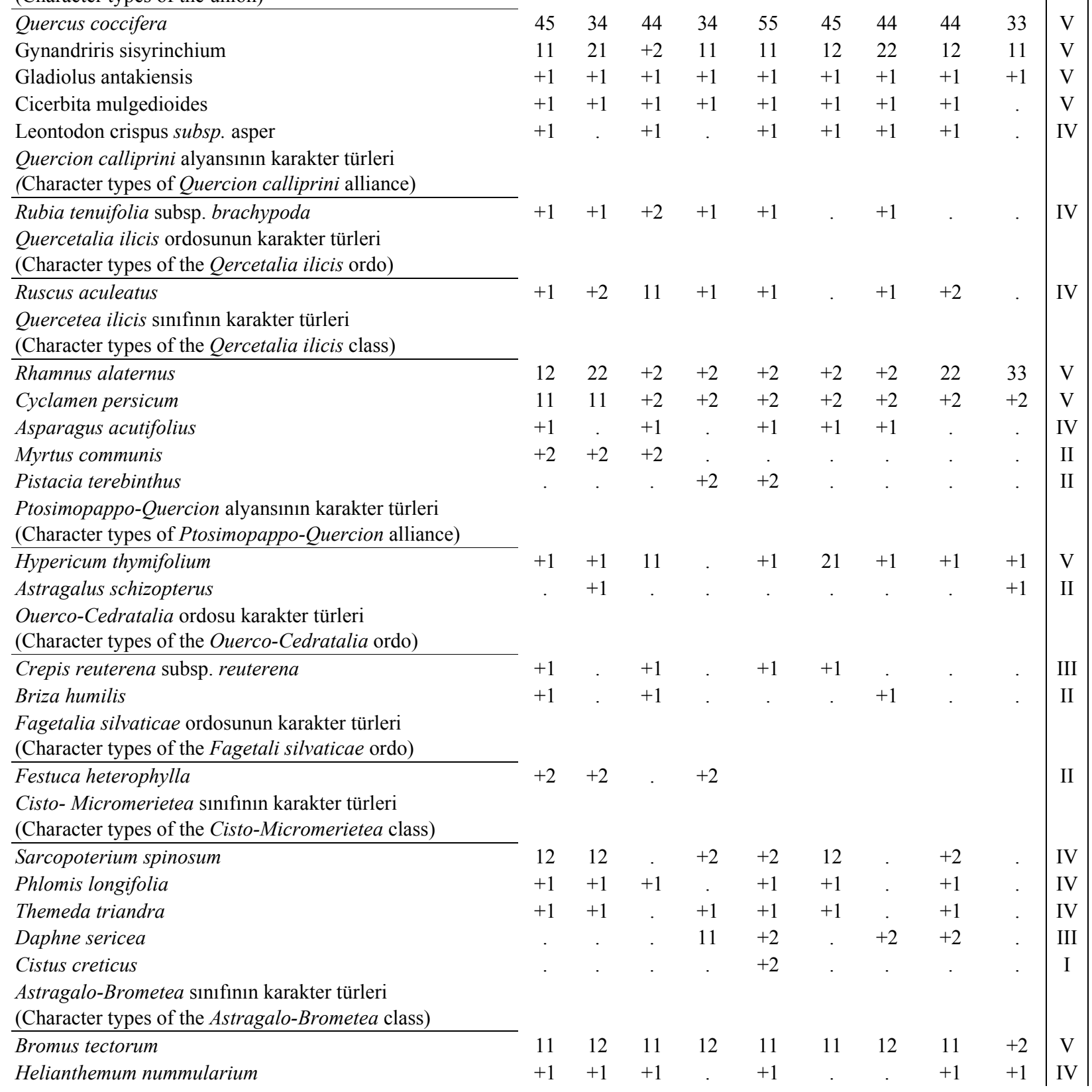


Çizelge 3. Devam

Table 3. Continued

Diğerleri (Others)

\begin{tabular}{|c|c|c|c|c|c|c|c|c|c|c|}
\hline Piptatherum miliaceum & 11 & 21 & 21 & 21 & 11 & 11 & 21 & 11 & 11 & $\mathrm{~V}$ \\
\hline Dactylis glomerata & +2 & 12 & 11 & 11 & 11 & 11 & 12 & 12 & 11 & $\mathrm{~V}$ \\
\hline Lolium perenne & +1 & +2 & +1 & +1 & +1 & +1 & +1 & +1 & +1 & $\mathrm{~V}$ \\
\hline Catapodium rigidum & +1 & +1 & +1 & +1 & +1 & +1 & . & +1 & +1 & $\mathrm{~V}$ \\
\hline Crepis sancta & +1 & +1 & +1 & +1 & +1 & +1 & . & +1 & +1 & $\mathrm{~V}$ \\
\hline Tordylium syriacum & +1 & +1 & +1 & +1 & +1 & +1 & +1 & +1 & . & $\mathrm{V}$ \\
\hline Genista acanthoclada & . & . & +2 & 11 & +2 & +2 & 11 & 22 & +2 & IV \\
\hline Erodium laciniatum & +1 & +1 & +1 & +1 & . & +1 & +1 & +1 & . & IV \\
\hline Euophorbia taurensis & +1 & +1 & . & +1 & +1 & . & . & +1 & +1 & IV \\
\hline Minuartia mesogitana & +1 & 11 & +1 & . & . & 11 & . & +1 & 11 & IV \\
\hline Stipa bromoides & . & +2 & +1 & +1 & . & +1 & . & +1 & +1 & IV \\
\hline Salvia viridis & +1 & +1 & +1 & +1 & +1 & . & . & . & +1 & IV \\
\hline Crepis zacintha & +1 & . & +1 & +1 & +1 & +1 & . & . & +1 & IV \\
\hline Legousia falcata & +1 & +1 & +1 & . & +1 & +1 & +1 & . & . & IV \\
\hline Anchusa azurea & +1 & . & +1 & +1 & +1 & +1 & +1 & . & . & IV \\
\hline Trifolium repens & +1 & . & . & +1 & . & +1 & . & +1 & +1 & III \\
\hline Pancratium maritimum & +1 & +1 & . & +1 & . & . & +1 & . & +1 & III \\
\hline Trifolium angustifolium & +1 & . & . & +1 & +1 & +1 & . & . & +1 & III \\
\hline Galium cassium & . & . & +1 & +1 & . & 11 & 11 & +1 & . & III \\
\hline Linum corymbulosum & . & . & +1 & +1 & +1 & +1 & +1 & . & . & III \\
\hline Geranium rotundifolium & +1 & . & +1 & . & +1 & . & . & . & +1 & III \\
\hline Torilis arvensis subsp. purperea & +1 & +1 & . & +1 & . & . & +1 & . & . & III \\
\hline Ornithogalum sphaerocarpum & +1 & +2 & . & +1 & +1 & . & . & . & . & III \\
\hline Anagallis arvensis & +1 & . & +1 & +1 & . & . & . & . & +1 & III \\
\hline Valantia hispida & +1 & +1 & . & . & . & +1 & . & . & +1 & III \\
\hline Ononis natrix & +1 & . & . & . & . & +1 & +1 & . & +1 & III \\
\hline Vaccaria pyramidata & +1 & +1 & . & . & . & . & +1 & +1 & . & III \\
\hline Tragopogon longirostris & . & . & +1 & . & +1 & +1 & . & . & +1 & III \\
\hline Dianthus strictrus & +1 & +1 & . & . & . & . & +1 & . & . & II \\
\hline Arum dioscoridis & +2 & +2 & . & . & . & . & +2 & . & . & II \\
\hline Lotus corniculatus & +1 & . & . & +1 & . & . & . & . & +1 & II \\
\hline Medicago coronota & +1 & . & +1 & . & . & . & . & +1 & . & II \\
\hline Steptorhamphus tuberosus & +1 & +1 & . & . & . & . & . & +1 & . & II \\
\hline Cicerbita racemosa & . & . & . & +1 & . & . & +1 & +1 & . & II \\
\hline Anthyllis tetraphylla & +1 & +1 & . & . & . & . & +1 & . & . & II \\
\hline Lotus peregrinus subsp. peregrinus & . & +1 & . & . & . & +1 & . & . & . & II \\
\hline Galium floribundum subsp. floribundum & 11 & . & . & . & . & . & 11 & . & . & II \\
\hline Plantago scabra & +1 & +1 & . & . & . & . & . & . & . & II \\
\hline Anarrhinum orientale & . & . & . & +1 & . & . & +1 & . & . & II \\
\hline Avena sterilis & +1 & . & . & . & . & . & . & . & . & $\mathrm{I}$ \\
\hline Hippocrepis unisiliquosa & +1 & . & . & . & . & . & . & . & . & I \\
\hline Ononis viscosa & . & . & . & . & +1 & . & . & . & . & $\mathrm{I}$ \\
\hline
\end{tabular}

${ }^{*}$ B: Bat1 (W: West).

\section{Myrto-Quercetum cocciferae birliği}

Quercus coccifera bu kez de alandaki ilk vadinin 250-400 metrelerindeki kuzey yamaçlarında Myrtus communis L. ile birlik oluşturmuştur. Burası tuzlu batı rüzgarlarından etkilenmediği gibi rakım nedeniyle de farklı ekolojik koşullar bitkilerin vitalitesini arttırmış ve floristik kompozisyonda değişmeye yol açmıştır. Böylece Cerotonia siliqua L., Lavatera punctata L. ve Serratula cerinthifolia (Sm.) Boiss. türleri de birlik içerisinde yüksek 
tekerrürlü olduklarından karakter tür seçilmiştir (Çizelge 4).

Birliğin habitat topraklarında \% 100 örtüşe varan sıklıkla orantılı olarak, bariz bir A horizonu gelişmiş ve organik madde artmıştır. Bu durum toprakta su tutma kapasitesi ve $\mathrm{pH}$ ' nın yükselmesine, kireç miktarının ise düşmesine neden olmuştur. Böyle habitatlarda yer yer 3,5 m kadar boylanan makiler rupikol karakterli arazinin \% 50 eğimine rağmen erozyonu nispeten azaltmıştır. Ancak insanların bitkileri yakacak için kestikleri ve apikal meristemleri karakeçi sürüsünün tehdidi altında olan alanlarda $100 \mathrm{~cm}$ 'den fazla boylanamamıștır. GPS koordinatları N. $35^{\circ} 59^{\prime} 535^{\prime \prime}$ ve E. $35^{\circ} 59^{\prime}$ $937^{\prime \prime}$ olan birlik habitatlarında 22 Nisan-10 Mayıs 2005 tarihlerinde 11 örnek parsel yapılarak floristik sisteme göre ekolojik olarak değerlendirilmiştir. Diğer birlikler gibi Akdeniz fitocoğrafik bölgesinin karakteri olan sintaksonlarda yer alan birlik, Quercion calliprini Zohary (1962) alyans1, Quercetalia ilicis BraunBlanquet (1947) ordosu ve Quercetea ilicis BraunBlanquet (1947) sınıfinda değerlendirilmiştir.

Çizelge 4. Myrto - Quercetum cocciferae birliği.

Table 4. Myrto - Quercetum cocciferae plant association.

\begin{tabular}{|c|c|c|c|c|c|c|c|c|c|c|c|c|}
\hline \\
\hline Örnek parsel no (Sample parcel number) & 23 & 24 & 22 & 18 & 25 & 19 & 21 & 20 & 26 & 27 & 28 & \multirow{2}{*}{ 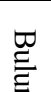 } \\
\hline Alan genişliği (Field width) $\left(\mathrm{m}^{2}\right)$ & 400 & 400 & 400 & 400 & 400 & 400 & 400 & 400 & 400 & 400 & 400 & \\
\hline Yükseklik (Height) (m) & 120 & 150 & 50 & 75 & 170 & 90 & 125 & 70 & 210 & 210 & 160 & E \\
\hline Yön (Direction) ${ }^{*}$ & $\mathrm{~K} / \mathrm{N}$ & $\mathrm{KB} / \mathrm{NW}$ & $\mathrm{K} / \mathrm{N}$ & $\mathrm{K} / \mathrm{N}$ & $\mathrm{KB} / \mathrm{NW}$ & $\mathrm{K} / \mathrm{N}$ & $\mathrm{K} / \mathrm{N}$ & $\mathrm{K} / \mathrm{N}$ & $\mathrm{B} / \mathrm{W}$ & $\mathrm{B} / \mathrm{W}$ & $\mathrm{B} / \mathrm{W}$ & $\begin{array}{l}\tilde{E} \\
\varrho\end{array}$ \\
\hline Eğim (Slope) $\left(^{\mathrm{O}}\right)$ & 50 & 40 & 25 & 65 & 65 & 50 & 65 & 40 & 65 & 65 & 65 & 声 \\
\hline Anakaya (Bedrock) & \multicolumn{11}{|c|}{ Kireçtaşı (Limestone) } & $\overparen{0}$ \\
\hline Genel örtüş (General overlap) (\%) & 100 & 95 & 90 & 100 & 100 & 100 & 85 & 100 & 90 & 90 & 85 & $\stackrel{\mathscr{W}}{\mathscr{Q}}$ \\
\hline Çalı örtüş (Shrub overlap) (\%) & 100 & 95 & 90 & 100 & 100 & 100 & 80 & 100 & 85 & 90 & 75 & $\overparen{8}$ \\
\hline Çalı boyu (Shrub lenght) (cm) & 200 & 120 & 250 & 350 & 120 & 400 & 250 & 300 & 130 & 130 & 100 & 荧 \\
\hline Ot örtüş (Grass overlap)(\%) & 20 & 30 & 10 & 5 & 20 & 5 & 35 & 5 & 30 & 30 & 35 & \\
\hline \multicolumn{13}{|l|}{$\begin{array}{l}\text { Birliğin karakter türleri } \\
\text { (Character types of the union) }\end{array}$} \\
\hline Quercus coccifera & 34 & 33 & 33 & 22 & 33 & 12 & 22 & 34 & 44 & 44 & 33 & $\mathrm{~V}$ \\
\hline Myrtus communis & 22 & 33 & 12 & 11 & 33 & 33 & 33 & 11 & 22 & 11 & 33 & $\mathrm{~V}$ \\
\hline Ceratonia siliqua & 12 & 22 & 22 & +2 & 12 & 22 & +2 & . & 22 & 12 & +2 & $\mathrm{~V}$ \\
\hline Lavatera punctata & +1 & +1 & . & . & +1 & . & +1 & +1 & +1 & +1 & 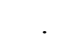 & IV \\
\hline Serratula cerinthifolia & +1 & +1 & +1 & . & +1 & . & +1 & +1 & . & & 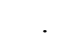 & III \\
\hline \multicolumn{13}{|l|}{$\begin{array}{l}\text { Quercion calliprini alyansinin karakter türleri } \\
\text { (Character types of Quercion calliprini alliance) }\end{array}$} \\
\hline Arbutus andrachne & +2 & +2 & 22 & 12 & 12 & . & 12 & . & 11 & +2 & +2 & $\mathrm{~V}$ \\
\hline Rubia tenuifolia subsp. brachypoda & +1 & +1 & . & +1 & . & . & 11 & . & . & . & . & II \\
\hline \multicolumn{13}{|l|}{$\begin{array}{l}\text { Quercetalia ilicis ordosunun karakter türleri } \\
\text { (Character types of the Qercetalia ilicis ordo) }\end{array}$} \\
\hline Phillyrea latifolia & 11 & +2 & 22 & +2 & . & . & . & . & . & . & ${ }^{\circ}$ & II \\
\hline Geranium purpureum & +1 & +1 & . & . & . & +1 & . & . & . & . & . & II \\
\hline Cercis siliquastrum & . & . & . & +2 & . & +2 & . & . & . & . & . & I \\
\hline \multicolumn{13}{|l|}{$\begin{array}{l}\text { Quercetea ilicis sınıfının karakter türleri } \\
\text { (Character types of the Qercetalia ilicis class) }\end{array}$} \\
\hline Cyclamen persicum & +1 & +1 & 11 & +1 & +1 & +1 & +2 & +2 & +1 & +2 & 11 & $\mathrm{~V}$ \\
\hline Pistacia terebinthus & 33 & +1 & 22 & 33 & . & 33 & 11 & . & . & +2 & +2 & IV \\
\hline Smilax aspera & . & +1 & 12 & +2 & +1 & +2 & 11 & +2 & +1 & . & . & IV \\
\hline Rhamnus alaternus & . & . & +2 & 12 & . & +2 & +2 & . & . & . & 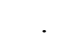 & II \\
\hline Asparagus acutifolius & . & . & +1 & . & . & +1 & . & +1 & . & +1 & . & II \\
\hline Melica eligulata & . & +1 & . & . & . & . & +1 & . & . & . & +1 & II \\
\hline Jasminium fruticans & . & & . & . & 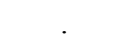 & 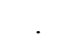 & . & - & . & . & +1 & $\mathrm{I}$ \\
\hline
\end{tabular}


Çizelge 4. Devam

Table 4. Continued

Ptosimopappo-Quercion alyansının karakter türleri

(Character types of Ptosimopappo-Quercion

alliance)

\begin{tabular}{|c|c|c|c|c|c|c|c|c|c|c|c|c|}
\hline Hypericum thymifolium & 11 & 11 & +1 & 11 & 21 & +2 & 21 & . & 21 & 21 & 21 & $\mathrm{~V}$ \\
\hline Astragalus schizopterus & +1 & . & . & +1 & . & . & & . & . & . & & $\mathrm{I}$ \\
\hline \multicolumn{13}{|c|}{$\begin{array}{l}\text { Fagetalia silvaticae ordosunun karakter türleri } \\
\text { (Character types of the Fagetali silvaticae ordo) }\end{array}$} \\
\hline Festuca heterophylla & . & +2 & +2 & 11 & 11 & 11 & . & 11 & 11 & 11 & 11 & $\mathrm{~V}$ \\
\hline \multicolumn{13}{|c|}{$\begin{array}{l}\text { Quercetea pubescentis sinıfinın karakter türleri } \\
\text { (Character types of the Quercetea pubescentis } \\
\text { class) }\end{array}$} \\
\hline Hedera helix & +1 & +1 & +2 & +1 & +1 & +1 & . & +1 & +1 & 11 & 11 & $\mathrm{~V}$ \\
\hline Cotinus coggyrea & +2 & 22 & . & . & +2 & 12 & & 12 & 11 & 22 & 22 & IV \\
\hline Styrax officinalis & . & . & +2 & . & . & . & +2 & . & . & . & . & I \\
\hline Coronilla emerus subsp. emeroides & . & . & . & . & . & +1 & . & . & . & . & . & I \\
\hline \multicolumn{13}{|c|}{$\begin{array}{l}\text { Cisto- micromerietea sinıfinın karakter türleri } \\
\text { (Character types of the Cisto-Micromerietea class) }\end{array}$} \\
\hline Micromeria myrtifolia & +1 & +1 & +1 & . & +1 & . & +1 & +1 & . & +1 & +1 & IV \\
\hline Daphne sericea & +2 & +2 & . & 33 & +2 & . & . & . & . & +2 & +2 & III \\
\hline Cistus creticus & +2 & 11 & . & . & 22 & . & . & . & 11 & 22 & . & III \\
\hline Spartium junceum & +1 & +1 & . & . & . & +2 & 12 & +2 & . & . & . & III \\
\hline Themeda triandra & . & . & +2 & . & . & . & +2 & . & . & . & . & I \\
\hline Phlomis longifolia subsp. longifolia & . & . & . & . & . & . & . & . & +1 & +1 & . & I \\
\hline Origanum syriacum & . & . & +1 & . & . & . & +1 & . & . & . & . & I \\
\hline Salvia tomentosa & . & +1 & . & . & . & . & . & . & . & . & . & I \\
\hline \multicolumn{13}{|c|}{$\begin{array}{l}\text { Astrogalo-Brometea sinıfinın karakter türleri } \\
\text { (Character types of the Astragalo-Brometea class) }\end{array}$} \\
\hline Bromus tectorum & 11 & 11 & +2 & 11 & +2 & 11 & . & 11 & 11 & 11 & +1 & $\mathrm{~V}$ \\
\hline Helianthemum nummularium & . & . & . & . & +1 & . & . & . & +1 & . & . & I \\
\hline \multicolumn{13}{|l|}{ Diğerleri (Others) } \\
\hline Lolium perene & +1 & +1 & +1 & +1 & +1 & +1 & +1 & +1 & +1 & +1 & +1 & $\mathrm{~V}$ \\
\hline Dactylis glomerata & 11 & 11 & . & +1 & 11 & +1 & . & +1 & 11 & 11 & 11 & $\mathrm{~V}$ \\
\hline Stipa bromoides & +1 & +1 & . & +1 & +1 & +1 & . & +1 & +1 & +1 & +1 & $\mathrm{~V}$ \\
\hline Aegilops umbellulata & +1 & +1 & +1 & . & +1 & . & +1 & . & +1 & +1 & +1 & IV \\
\hline Lotus peregrinus var. peregrinus & +1 & . & +1 & +1 & . & +1 & +1 & +1 & +1 & . & . & IV \\
\hline Genista acanthoclada & +2 & 22 & . & . & 22 & . & +2 & . & 11 & . & +2 & III \\
\hline Andropogon ischaemum & 11 & +2 & . & . & 21 & . & . & . & 22 & 22 & 11 & III \\
\hline Carthamus lanatus & . & . & +1 & . & +1 & . & +1 & +1 & +1 & . & . & III \\
\hline Centaurium pulchellum & +1 & +1 & +1 & . & +1 & . & +2 & . & . & . & . & III \\
\hline Bupleurum rotundifolium & +1 & +1 & +1 & . & . & . & . & . & . & +1 & . & II \\
\hline Dorycnium hirsutum & . & +1 & . & . & +1 & . & . & . & . & +1 & +1 & II \\
\hline Cystopteris fragilis & . & . & +2 & +2 & . & +2 & +2 & . & . & . & . & II \\
\hline Anarrhinum oriantale & +1 & +1 & . & . & . & . & . & +1 & . & +1 & . & II \\
\hline Medicago coronota & . & . & +1 & . & +1 & . & +1 & . & +1 & . & . & II \\
\hline Minuartia mesogitana & +1 & . & . & . & +1 & . & . & +1 & . & . & +1 & II \\
\hline Galium verum & +1 & +1 & . & . & . & . & . & . & +1 & . & +1 & II \\
\hline Micromeria graeca & +1 & . & . & . & . & +1 & +1 & . & . & . & . & II \\
\hline Ruta chalepensis & . & . & . & +1 & . & +1 & 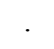 & +1 & . & . & . & II \\
\hline Tordylium syriacum & . & . & +1 & +1 & . & . & & +1 & . & . & . & II \\
\hline Ononis natrix & . & +1 & . & . & +1 & . & & . & +2 & . & . & II \\
\hline
\end{tabular}


Çizelge 4. Devam

Table 4. Continued

Bromus sterilis

Crucianenella latifolia

Valerianella coronata

Torilis arvensis subsp. purperea

Linaria chalepensis

Carduus pycnocephalus

Allium rubellum

Anagallis arvensis

Catapodium rigidum

Crepis zacintha

Trifolium angustifolium

Mercurialis annua

Campanula saxonorum

Campanula strigosa

Umbilicus horizontalis

Dryopteris pallida

Galium canum

Pterocephalus plumosus

Bromus japonicus

Centaurium erythraea

Pallenis spinosa

Trifolium campestre

Raphanus raphanistrum

Arum dioscoridis

Galium floribundum subsp. floribundum

Euphorbia taurensis

Geranium rotindifolium

Convolvulus centabrica

Salvia viridis

Lotus corniculatus

Anthyllis tetraphylla

Trifolium repens

Linum corymbulosum

Sedum pallidum

Ptilostemon chamaepeuce

Rhagadiolus stellata

Origanum vulgare

Picris hieracioides

Linum nodiflorum

Linum pubescens

Aetheorhiza bulbosa

Lotus corniculatus

Alkanna confusa

${ }^{*}$ K: Kuzey, KB: Kuzeybatı, B: Batı (N: North, NW: Northwest, W: West).

\section{Andropogo- Quercetum cocciferae birliği}

Birlik araştırma alanının \% 40-50 eğimli ve 90250 metrelerdeki batı yamaçlarında seyrek bir yayılış göstermiştir. Çünkü yamaçlar sarp ve engebeli olup insan tahribine müsait değilse de burada iki önemli olumsuz faktör vardır. Birisi bölgenin denizden esen hâkim batı rüzgârının habitatı olumsuz etkilemesi, yaz kuraklığında neden olduğu transprasyona cevap veremeyen çoğu otsu bitkilerin selekte olmasına ve yaprakları 
kalın mum tabakası ile kaplı olmayan odunsu bitkilerin de bodur kalmasına yol açmıştır. Diğeri de seyrek örtüşlü habitatta çakıl ve taşlar belli sahalarda gruplaşmış olup birden fazla kanallardan akarak birleștikleri için bu çakıl yı ğınları bitki örtüsünden yoksundur. Böylece rupikol karakterli habitat toprak erozyonuna elverişli olduğundan A horizonunun teşekkülünü de sağlayamamıştır. $\mathrm{Bu}$ yüzden toprağın organik maddece zayıf kalması, buna bağl1 olarak su tutma kapasitesinin düşmesine ve kireç miktarının artmasına yol açmıştır.

Yukarıdaki izah edilen ekolojik koşulların farklılığ1 nedeniyle Quercus coccifera alanın farklı mikroklimalarında farklı türlerle birlik olușturmaktadır. Bütün bunlar bu bitkinin bölgedeki maki türleri arasında ekolojik toleransı en yüksek olduğunu gösterir. Habitatın ekolojik özelliğine ve floristik sisteme uygun olarak birlikte 1srarla bulunan Akdeniz elementlerinden, Andropogon distacyos L., Olea europae var. sylvestris (Miller) Lehr. ve Helichrysum stoechas (L.) Moench türleri birliğe karakter tür olarak seçilmiştir (Çizelge 5). GPS koordinatlar1 N. $36^{\circ} 00^{\prime} 122^{\prime \prime}$ ve E. $35^{\circ} 58^{\prime}$ $558^{\prime \prime}$ olan birlik sintaksonomik yönden diğerleri gibi Akdeniz kökenli Quercion calliprini Zohary (1962) alyans1, Quercetalia ilicis Braun-Blanquet (1947) ordosu ve Quercetea ilicis Braun-Blanquet (1947) sınıfında değerlendirilmiştir.

Çizelge 5. Andropogo - Quercetum cocciferae birliği.

Table 5. Andropogo - Quercetum cocciferae plant association.

\begin{tabular}{l} 
Örnek parsel no (Sample parcel number) \\
Alan genişliği (Field width) $\left(\mathrm{m}^{2}\right)$ \\
Yükseklik (Height)(m) \\
Yön (Direction) \\
Eğim (Slope) $\left.{ }^{\mathrm{O}}{ }^{\mathrm{O}}\right)$ \\
Anakaya (Bedrock) \\
Genel örtüş (General overlap) (\%) \\
Çalı örtüs (Shrub overlap) (\%) \\
Çalı boyu (Shrub lenght) (cm) \\
Ot örtüş (Grass overlap)(\%) \\
\hline Birliğin karakter türleri \\
(Character types of the union) \\
\hline Quercus coccifera \\
Andropogon distachyos \\
Olea europaea subsp. sylvestris \\
Helichrysum stoechas \\
Quercion calliprini alyansının karakter türleri \\
(Character types of Quercion calliprini alliance) \\
\hline Rubia tenuifolia subsp. brachypoda \\
Arbutus andrachne \\
Quercetalia ilicis ordosunun karakter türleri \\
(Character types of the Qercetalia ilicis ordo) \\
\hline Ceratonia siliqua \\
Quercetea ilicis sinıfının karakter türleri \\
(Character types of the Qercetalia ilicis class) \\
\hline Rhamnus alaternus \\
Pistacia terebinthus \\
Myrtus communis \\
Cyclamen persicum \\
Asparagus acutifolius \\
Jasminum fruticans \\
Smilax aspera \\
Ptosimopappo-Quercion alyansının karakter türleri \\
(Character types of Ptosimopappo-Quercion alliance) \\
\hline
\end{tabular}

\begin{tabular}{|c|c|c|c|c|}
\hline 36 & 35 & 37 & 38 & 39 \\
\hline 400 & 400 & 400 & 400 & 400 \\
\hline 130 & 90 & 150 & 200 & 250 \\
\hline B-W & B-W & B-W & $\mathrm{B}-\mathrm{W}$ & B-W \\
\hline 45 & 45 & 40 & 50 & 50 \\
\hline \multicolumn{5}{|c|}{ Kireçtaşı (Limestone) } \\
\hline 80 & 80 & 90 & 70 & 90 \\
\hline 65 & 70 & 85 & 70 & 85 \\
\hline 200 & 200 & 200 & 150 & 200 \\
\hline 45 & 30 & 30 & 25 & 25 \\
\hline
\end{tabular}

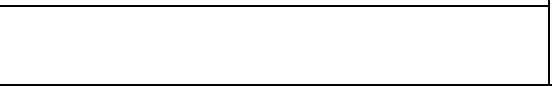

\begin{tabular}{ccccc|c}
23 & 33 & 33 & 33 & 23 & $\mathrm{~V}$ \\
12 & 11 & 11 & 11 & 11 & $\mathrm{~V}$ \\
12 & 12 & 22 & 11 & 22 & $\mathrm{~V}$ \\
+2 & +1 & +1 & +1 &. & IV
\end{tabular}

$\begin{array}{lllll}+1 & +1 & +1 & \text {. } & \text {. }\end{array}$

\begin{tabular}{ccccc}
+1 & +1 & $\cdot$ & $\cdot$ \\
\hline &. &. & +2 & +2
\end{tabular}

$\begin{array}{llllll}+2 & +2 & +2 & . & \text {. }\end{array}$

\begin{tabular}{ccccc|c|}
+2 & +2 & +2 & $\cdot$ & $\cdot$ & III \\
& & & & & \\
22 & 12 & 12 & 12 & 12 & $\mathrm{~V}$ \\
+2 & +2 & 12 & 11 & +2 & $\mathrm{~V}$ \\
11 & 12 & 12 & +2 & 22 & $\mathrm{~V}$ \\
+2 & +1 & +1 & +1 & +2 & $\mathrm{~V}$ \\
+1 & $\cdot$ & +1 & $\cdot$ & +1 & III \\
+1 & +1 & +2 & $\cdot$ & $\cdot$ & III \\
$\cdot$ & $\cdot$ & +1 & $\cdot$ & +1 & II \\
& & & & &
\end{tabular}


Çizelge 5. Devam

Table 5. Continued

Astragalus schizopterus

$+1 \quad+1$

Fagetalia silvaticae ordosunun karakter türleri

(Character types of the Fagetali silvaticae ordo)

Festuca heterophylla

11

Quercetea pubescentis Sinıfının Karakter Türleri

(Character types of the Quercetea pubescentis class)

Cotinus coggyrea

Coronilla emerus subsp. emeroides

Cisto Micromerietea sınıfının karakter türleri

(Character types of the Cisto-Micromerietea class)

Cistus creticus

Micromeria myrtifolia

Spartium junceum

Astragalo-Brometea sinıfinın karakter türleri

(Character types of the Astragalo-Brometea class)

Bromus tectorum
Helianthemum nummularium
Diğerleri (Others)

Genista acanthoclad

Dactylis glomerata

Ruta chalepensis

Stipa bromoides

Lolium perenne

Carthamus lanatus

Trifolium angustifolium

Tordylium syriacum

Galium cassium

Linum corymbulosum

Dorycnium hirsutum

Galium verum

Lamium amplexicaule

Lotus corniculatus

Medicago coronota

Crucianella latifolia

Torilis arvensis

Trifolium campstre

Piptatherum miliaceum

Medicago polymorpha

Linaria chalepensis

Dianthus strictrus

Aegilops umbellulata

Anthylis tetraphylla

Trifolium repens

Ononis natrix

Linum nodiflorum

Linum pubescens

B: Batı (W: West).

$+2 \quad+2$

$+1 \quad+1$$$
12+2
$$$$
\text { . }
$$$$
+
$$

$$
+1
$$$$
+
$$$$
+1
$$$$
+1
$$$$
+1+
$$$$
+1 \quad+1
$$$$
+1
$$$$
+1
$$$$
+1 \quad+1 \quad+1
$$$$
\begin{array}{llllll}
+1 & +1 & . & +1 & & \text { III } \\
+1 & & & +1 & +1 &
\end{array}
$$$$
\begin{array}{lllllll}
+1 & . & & +1 & +1 & . & \text { III }
\end{array}
$$

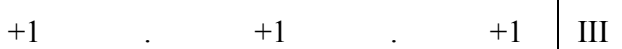$$
\begin{array}{lllllll}
. & +1 & +1 & +1 & . & \text { III }
\end{array}
$$

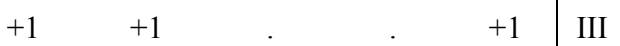$$
\begin{array}{llllll}
11 & . & . & 11 & 11 & \text { III }
\end{array}
$$$$
\begin{array}{ccccc|c}
11 & \cdot & \cdot & 11 & 11 & \text { III } \\
+1 & +1 & & &
\end{array}
$$

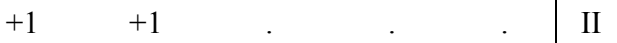

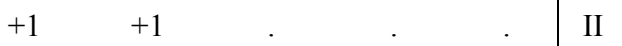$$
\begin{array}{ccccc}
+1 & + & + & \cdot & \\
\hline & +1 & +1 & &
\end{array}
$$

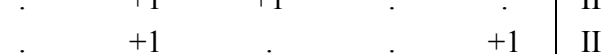

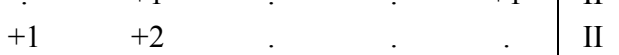

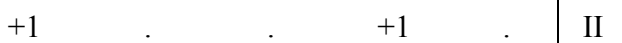$$
\begin{array}{llllllll}
+1 & +2 & \text {. } & & & \text {. } & \text {. } & \text { II }
\end{array}
$$

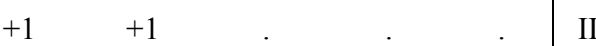$$
+1
$$ 


\section{Genisto-Spartietum juncei birliği}

Spartium junceum L bitkisi nispeten serin habitatları tercih ettiğinden, ilk iki vadi arasında doğuya yükselen bayırın kuzeye bakan yamaçlarında birlik oluşturmuştur. Yamacin güneş alan fazla eğimli kserofit kısımlarında Genista acanthoclada DC. ko-dominant duruma geçmiştir. Böylece her iki bitki habitatı \% 90-100 örterek 1ş1k rekabetinden dolayı floristik kompozisyonun zayıf kalmasına neden olmuştur. Bu özel mikroklimada sık tekerrür eden Ainsworthia trachycarpa Boiss., Ferulago cassia Boiss. ve Michauxia campanuloides L'Herit Exaiton Doğu Akdeniz elementleri olup birliğin diğer karakter türleridir (Çigelge 6).
Genelde dominant ve ko-dominant şeklinde iki farklı türden oluşan birliklerde türlerin örtüş bollukları bireysel olmasına rağmen burada Spartium ve Genista daha çok gruplar halinde habitatı paylaşmışlardır. Bu ilginç özellik, habitatın güneşlenme durumu ile toprak yapısı ve derinliğinden kaynaklanır. GPS koordinatları N. $35^{\circ} 59^{\prime} 941^{\prime \prime}$ ve E. $35^{\circ} 58^{\prime} 858^{\prime \prime}$ olan birlik 6 örnek parsel yapılarak tanımlanmıştır. Sintaksonomik olarak da Akdeniz fitocoğrafik orijinli Quercion calliprini Zohary (1962) alyans1, Quercetalia ilicis Braun-Blanquet (1947) ordosu ve Quercetea ilicis Braun-Blanquet (1947) sınıfında değerlendirilmiştir.

Çizelge 6. Genisto - Spartietum juncei birliği.

Table 6. Genisto - Spartietum juncei plant association.

\begin{tabular}{|c|c|c|c|c|c|c|c|}
\hline Örnek parsel no (Sample parcel number) & 42 & 40 & 41 & 43 & 45 & 44 & \\
\hline Alan genişliği (Field width) $\left(\mathrm{m}^{2}\right)$ & 400 & 400 & 400 & 400 & 400 & 400 & $\stackrel{\square}{\Xi}$ \\
\hline Yükseklik (Height)(m) & 250 & 220 & 230 & 275 & 310 & 290 & $\bar{E}$ \\
\hline Yön (Direction) ${ }^{*}$ & $\mathrm{~KB} / \mathrm{NW}$ & $\mathrm{B} / \mathrm{W}$ & $\mathrm{KB} / \mathrm{NW}$ & $\mathrm{KB} / \mathrm{NW}$ & $\mathrm{KB} / \mathrm{NW}$ & $\mathrm{KB} / \mathrm{NW}$ & E \\
\hline Eğim (Slope) $\left({ }^{\mathrm{O}}\right)$ & 70 & 50 & 50 & 50 & 60 & 50 & $\stackrel{\varrho}{\partial}$ \\
\hline Anakaya (Bedrock) & \multicolumn{3}{|c|}{ Kireçtaş1 (Limestone) } & & & & 鬼声 \\
\hline Genel örtüş (General overlap) (\%) & 100 & 100 & 100 & 100 & 100 & 100 & ఫ્ટ \\
\hline Çalı örtüş (Shrub overlap) (\%) & 100 & 90 & 100 & 95 & 100 & 95 & $\stackrel{\mathbb{D}}{\circledR}$ \\
\hline Çalı boyu (Shrub lenght) (cm) & 350 & 200 & 300 & 350 & 350 & 350 & อี \\
\hline Ot örtüş (Grass overlap)(\%) & 10 & 25 & 20 & 10 & 15 & 20 & \\
\hline \multicolumn{8}{|l|}{$\begin{array}{l}\text { Birliğin karakter türleri } \\
\text { (Character types of the union) }\end{array}$} \\
\hline Spartium junceum & 33 & 22 & 34 & 34 & 34 & 33 & V \\
\hline Genista acanthoclada & 22 & 22 & 22 & 23 & +1 & 22 & V \\
\hline Ainsworthia trachycarpa & +1 & +1 & +1 & +1 & +1 & +1 & V \\
\hline Ferulago cassia & +1 & +1 & +1 & +1 & +1 & +1 & V \\
\hline Michauxia campanuloides & +1 & +1 & +1 & +1 & +1 & +1 & V \\
\hline \multicolumn{8}{|l|}{$\begin{array}{l}\text { Quercion calliprini alyansının karakter türleri } \\
\text { (Character types of Quercion calliprini alliance) }\end{array}$} \\
\hline Quercus coccifera & +2 & +2 & +2 & +2 & 12 & +2 & V \\
\hline Rubia tenuifolia subsp. brachypoda & +1 & . & +1 & +2 & +1 & +1 & $\mathrm{~V}$ \\
\hline Arbutus andrachne & 12 & +2 & 22 & . & +2 & +2 & $\mathrm{~V}$ \\
\hline \multicolumn{8}{|l|}{$\begin{array}{l}\text { Quercetalia ilicis ordosunun karakter türleri } \\
\text { (Character types of the Qercetalia ilicis ordo) }\end{array}$} \\
\hline Ceratonia siliqua & . & . & . & . & +2 & +2 & II \\
\hline \multicolumn{8}{|l|}{$\begin{array}{l}\text { Quercetea ilicis sınıfının karakter türleri } \\
\text { (Character types of the Qercetalia ilicis class) }\end{array}$} \\
\hline Cyclamen persicum & +2 & 11 & +2 & +2 & +2 & +2 & $\mathrm{~V}$ \\
\hline Pistacia terebinthus & +2 & 11 & 22 & 22 & 22 & 22 & V \\
\hline Smilax aspera & 11 & +2 & +2 & 11 & +2 & +2 & V \\
\hline Rhamnus alaternus & +2 & +2 & +2 & +2 & +2 & . & $\mathrm{V}$ \\
\hline Asparagus acutifolius & +1 & +1 & +1 & . & +1 & +1 & V \\
\hline Myrtus communis & 11 & 22 & . & . & . & . & II \\
\hline Melica eligulata & . & . & . & . & +1 & +1 & II \\
\hline Jasminum fruticans & . & 11 & . & . & . & . & I \\
\hline $\begin{array}{l}\text { Ptosimopappo-Quercion alyansının karakter türleri } \\
\text { (Character types of Ptosimopappo-Quercion alliance) }\end{array}$ & & & & & & & \\
\hline
\end{tabular}


Çizelge 6. Devam

Table 6. Continued

Hypericum thymifolium

11

Fagetalia silvaticae ordosunun karakter türleri

(Character types of the Fagetali silvaticae ordo)

\begin{tabular}{l} 
Festuca heterophylla \\
Quercetea pubescentis sınıfının karakter türleri \\
(Character types of the Quercetea pubescentis class) \\
\hline Cotinus coggyria \\
Cisto- Micromerietea sınıfının karakter türleri \\
(Character types of the Cisto-Micromerietea class) \\
\hline Cistus creticus \\
Psoralea bituminosa \\
Themeda triandra \\
Micromeria myrtifolia \\
Astragalo-Brometea sınıfinın karakter türleri \\
(Character types of the Astragalo-Brometea class) \\
\hline Bromus tectorum \\
Helianthemum nummularium \\
Diğerleri (Others)
\end{tabular}

Piptatherum miliaceum

Dactylis glomerata

Galium verum

Anagallis arvensis

Lolium perenne

Aegilops umbellulata

Stipa bromoides

Trifolium angustifolium

Tordylium syriacum

Carthamus lanatus

Pterocephalus plumosus

Sanquisorba minor

Trifolium repens

Linaria chalepensis

Dianthus strictus

Medicago coronata

Crucianella latifolia

Nepeta flavida

Thesium arvense

Cynogllossum creticum

${ }^{*}$ KB: Kuzeybat1, B: Bat1 (NW: Northwest, W: West).

\section{Myrto- Ericetum manupuliflorae birliği}

Erica manipuliflora Salise. bölgedeki iki vadi arasında doğuya yükselen bayırın sonlandığı doğu ve kuzey yamaçların 545-620 metrelerinde birlik

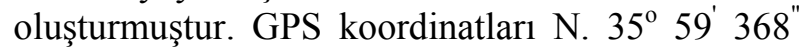
ve E. $36^{\circ} 00^{\prime} 321^{\prime \prime}$ olan birliğin ko-dominant türü Myrtus communis L. dir. Doğu Akdeniz elementi olan ve diğer birliklerde tekerrür etmeyen Rhamnus oleodies L. ssp. graecus (Bo1ss. et Reul) Holmboe ile Piptatherum coerulescens (Desf.) P. Beauv. karakter tür olarak seçilmiştir (Çizelge 7).

Birlik içerisinde çok zayıf ağaç katı oluşturan Pinus brutia Ten., geçmişte bölgenin hakim ormanı iken aşırı kesim sonucu regresiv gelişime 
geçmiştir. Akdeniz'in diğer sahilleri ve Ege sahillerinde olduğu gibi bu tahribat sonucu Erica hâkim duruma geçmiştir. Birlik habitatının doğu ve kuzey yönlerinin vadilere komşu olması, makilerde vitaliteyi olumlu etkilediğinden zemin örtüşünü de \% 100'e yükseltmiştir. Bu durum toprağın organik maddesini \% 13,2'ye yükseltirken, $\mathrm{pH}$ 's1 da 6,72 şeklinde hafif asitliğe yöneltmiștir. İnsan tahribi nedeniyle regresiv gelişimin devam etmesi nedeniyle birlik sintaksonomik olarak herhangi bir ordo ile temsil edilemedi. Ancak Quercion calliprini Zohary (1962) alyansı ile Quercetea ilicis BraunBlanquet (1947) sınıfında değerlendirilmiştir.

Çizelge 7. Myrto - Ericetum manupuliflorae birliği.

Table 7. Myrto - Ericetum manupuliflorae plant association.

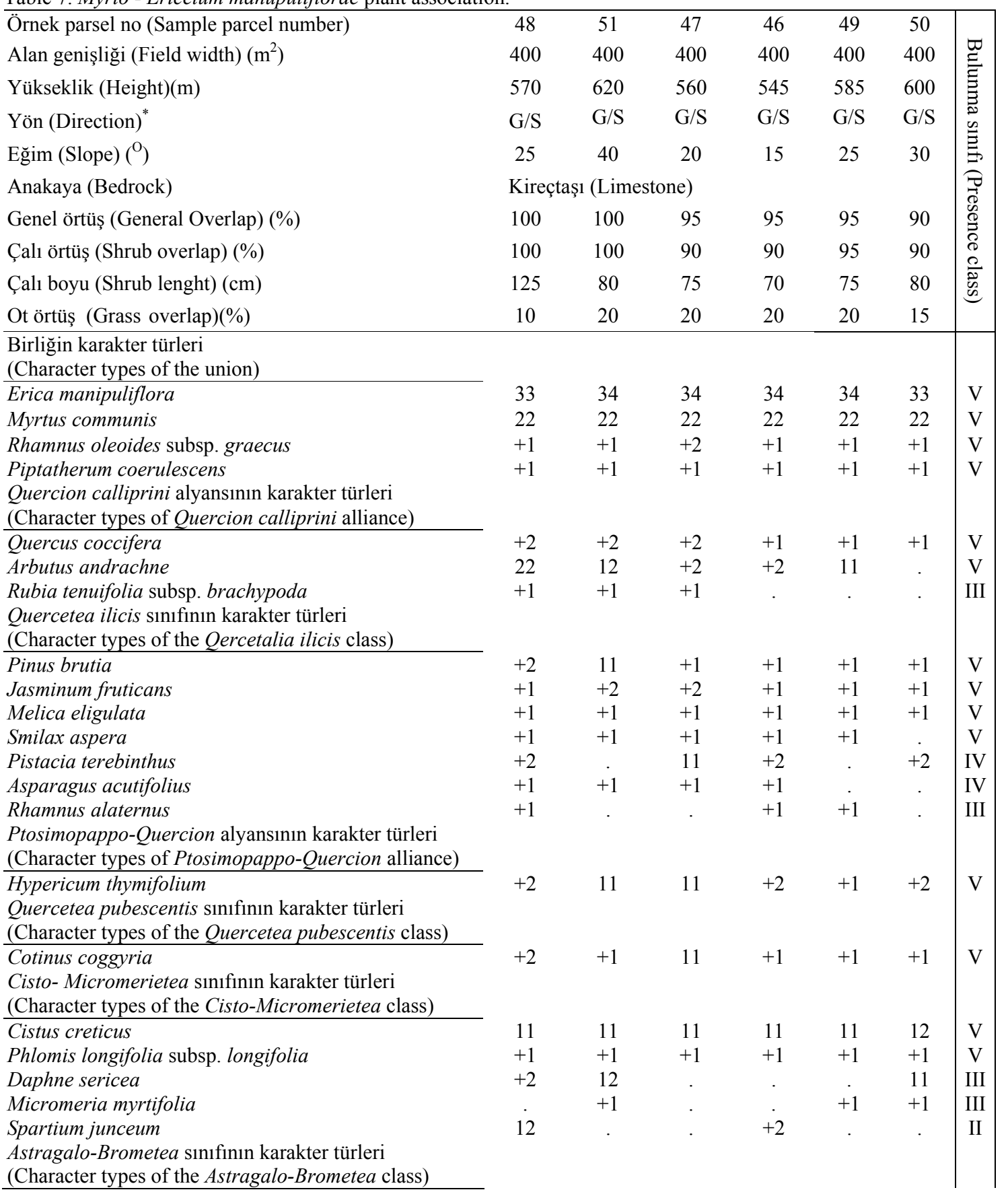




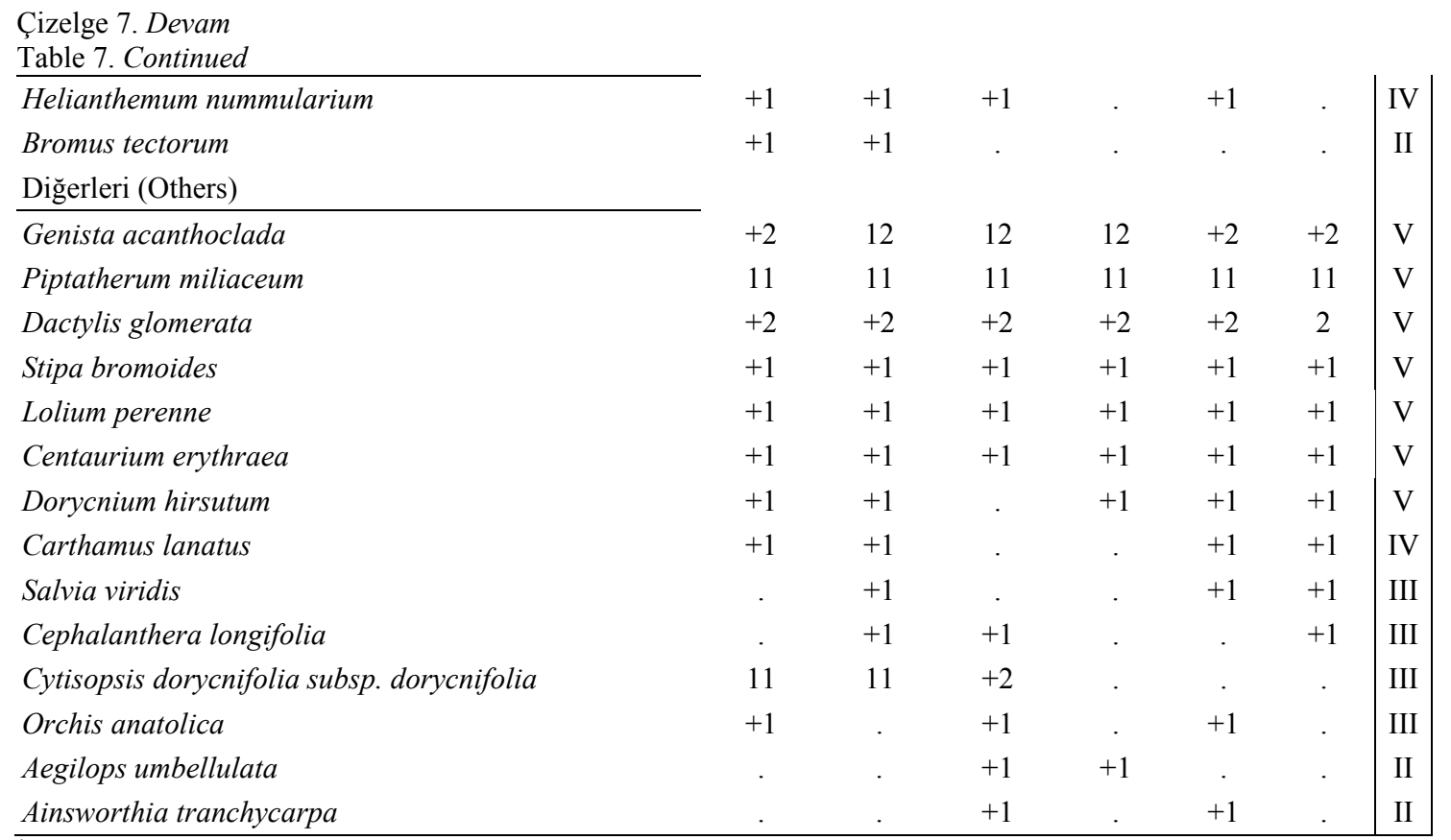

* G: Güney (S: South).

\section{Lauro-Arbutetum andrachne birliği}

Araştırma alanında vejetasyon yoğunluğunun ve bitkilerdeki vitalitenin en yüksek seviyedeki bitki birliği olup hâkim türü Arbutus andrachne L. dir. Birlik vadilerin kuzeye bakan güney yamaçların 210-350 metre 50-65 derece eğimli sarp arazide yayılmıştır. $\mathrm{Bu}$ durum vadinin açık tarafindan gelen hızlı rüzgârların bitkilerde aşırı transprasyonu engellediği gibi fotosentezin hızını da yükselterek bitkilerin boyca uzamasını kolaylaştırmıştır. Ayrıca toprak suyunun buharlaşmasını ve bitkilerin su stresi yaşamasını önleyerek büyüme ve gelişmelerini artırmıştır. Böylece örtüş-bolluk oranı yükselen bitkiler zemine uzun gün bitkilerin girişine izin vermediği için floristik kompozisyon zayıftır. $\mathrm{Bu}$ habitatta 1srarla bulunan ve örtü bolluğu yüksek Akdeniz elementi olan Laurus nobilis L. de kodominant olup birliğin belirleyici karakter türüdür.
Yine bu özel habitatta 1srarla bulunan Veronica leiocarpa Bo1ss. ve Asplenium adianthum-nigra L. higrofil bitkiler de birliğin diğer karakter türleridir (Çizelge 8).

Lauro-Arbutetum andrachne birliğinin bu özel ekolojik döngüsünde, habitat toprağında bariz A horizonu ve zengin organik madde oluşmuștur. $\mathrm{Bu}$ durum killi-tın bünyeli toprakta kireç miktarının düşmesini, $\mathrm{pH}$ 'ın asit yönünde yükselmesini ve su tutma kapasitesinin de artmasını sağlamıştır. GPS koordinatlar1 N. $36^{\circ} 00^{\prime} 912^{\prime \prime}$ ve E. $35^{\circ} 58^{\prime} 734^{\prime \prime}$ olan ve 6 örnek parsel yapılan birlik yukarıdaki ekolojik özellikleri nedeniyle, floristik açıdan da komşu birliklerden farklıdır. Vadinin bu mikroklimatik yapıs1, birliğin Ptosimopappo-Quercion Quézel, Barbero at Akman (1978) alyans1, Quercetalia ilicis Braun-Blanquet (1947) ordosu ve Quercetea ilicis Braun-Blanquet (1947) sınıfına dâhil etmiştir. 
Çizelge 8. Lauro-Arbutetum andrachne birliği.

Table 8. Lauro-Arbutetum andrachne plant association.

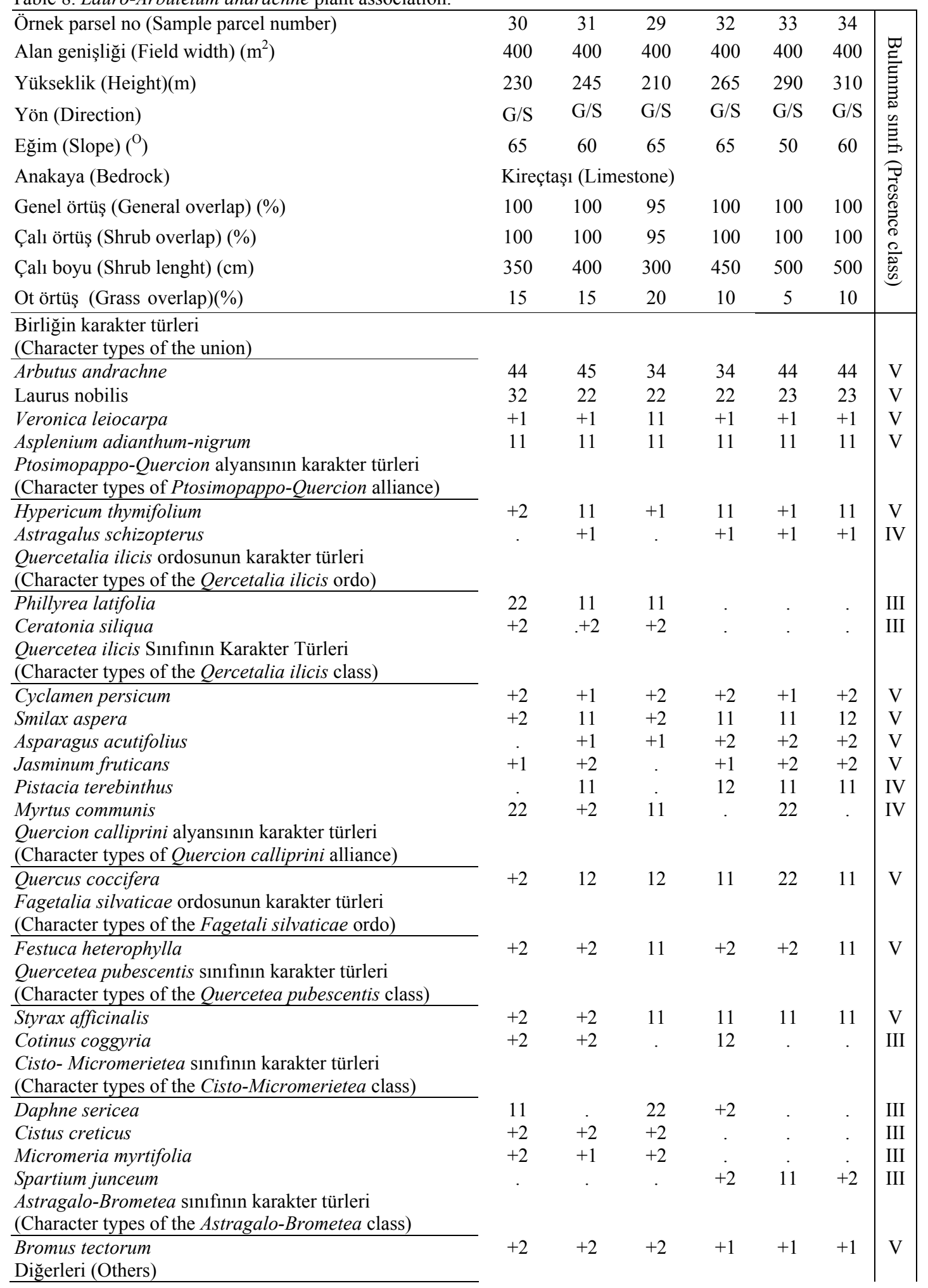


Çizelge 8. Devam

Table 8. Continued

\begin{tabular}{|c|c|c|c|c|c|c|c|}
\hline Piptatherum miliaceum & 11 & +2 & 11 & +2 & +2 & +2 & $\mathrm{~V}$ \\
\hline Dactylis glomerata & +2 & +2 & +2 & +2 & +1 & +1 & $\mathrm{~V}$ \\
\hline Lolium perenne & +1 & +1 & +1 & +1 & +1 & +1 & $\mathrm{~V}$ \\
\hline Dryopteris pallida & +2 & +2 & +2 & +1 & +1 & +2 & $\mathrm{~V}$ \\
\hline Stipa bromoides & +1 & +1 & . & +1 & +1 & +1 & V \\
\hline Ruta chalepensis & . & +1 & . & +1 & +1 & +1 & IV \\
\hline Aeligops umbellulata & . & +1 & +1 & +1 & +1 & . & IV \\
\hline Lotus corniculatus & +1 & +1 & +1 & +1 & . & . & IV \\
\hline Galium floribundum subsp. floribundum & +2 & +1 & +1 & . & . & . & III \\
\hline Trifolium angustifolium & +1 & +1 & +1 & . & . & . & III \\
\hline Trifolium campestre & +1 & +1 & +1 & . & . & e & III \\
\hline Dorycnium hirsutum & +1 & +1 & +1 & . & . & . & III \\
\hline Genista acanthoclada & +2 & . & +2 & . & . & . & II \\
\hline Polypogon viridis & +1 & . & +1 & . & . & . & II \\
\hline Salvia viridis & . & +1 & . & +1 & . & . & II \\
\hline Crepis sancta & +1 & +1 & . & . & . & . & II \\
\hline Crepis zacintha & +1 & . & +1 & . & . & . & II \\
\hline Linum corymbulosum & +1 & . & +2 & . & . & . & II \\
\hline Linum nodiflorum & +1 & . & +1 & . & . & . & II \\
\hline Galium verum & . & +1 & . & . & . & . & I \\
\hline Scandix pecten-veneris & . & +1 & . & . & . & . & I \\
\hline Catapodium rigidum & +1 & . & . & . & . & . & I \\
\hline Trifolium repens & . & & +1 & . & . & . & I \\
\hline Centaurium erythraea & +1 & & . & . & . & . & I \\
\hline
\end{tabular}

${ }^{*}$ G: Güney (S: South).

\section{SONUÇ VE ÖNERILER}

Araştırma alanı Fenik Yaylası Yayladağı ilçesine bağlı olmasına rağmen Samandağ ilçesi ve Akdeniz sahili ile sınır teşkil etmektedir. 2004-2007 yılları arasında vejetasyonun optimum geliştiği dönemlerde yapılan periyodik survey ve envanter çalışmalarıyla Fenik Yaylası ve çevresinin fitososyolojik ve ekolojik koşulları değerlendirilerek bu bölgede 7 bitki birliği tanımlanmıştır. Bitki birliklerinin floristik kompozisyonu ile iklim ve toprak verileri arasında mümkün olduğunca ilişki kurularak ekolojik değerlendirmeler yapılmıştır.

Belirlenen bitki birliklerinde toprağı tın ve killi tın bünyeli, ortalama organik maddesi yüksek olan alanlarda toprakta bariz bir A horizonu gelişmiştir.
$\mathrm{Bu}$ durum toprakta su tutma kapasitesinin artmasina kireç miktarının ise düşmesine neden olmuştur. Böyle habitatlarda 3,5 metreye kadar boylanan sik bitki örtüsü gelişmiş ve rupikol karakterli arazinin \% 50 eğimine rağmen toprak erozyonu azaltmıştır. Ancak kil ve kumlu-kil bünyeli topraklarda yayılıș gösteren birliklerde toprakta organik madde bariz olarak azalarak A horizonunun teşekkülünü sağlayamamıştır. Toprağın organik maddece zayıf kalması, buna bağlı olarak toprağın su tutma kapasitesinin düşmesine, kireç miktarının artmasına ve bitki örtüsünün seyrek örtüşlü olmasına yol açmıştır. Habitatta, çakıll ve taşların belli sahalarda gruplaştığ 1 alanlar bitki örtüsünden yoksundur. $\mathrm{Bu}$ durum rupikol karakterli habitatlarda toprak erozyonunu hızlandırmaktadır. 
İklim, yeryüzündeki tüm canlı ve cansız varlıkların yayılışına ve yaşamına etki eden en önemli faktördür. $\mathrm{Bu}$ nedenle iklimin sabit niş kullanan bitkiler için ayrı bir önemi vardır. $\mathrm{Bu}$ yüzden araştırma alanlarında iklim verilerinin belirlenmesi araştırmanın en önemli ekolojik yönünü oluşturmaktadır. İklim kavramı içerisinde dikkate alınması gereken en önemli faktörler sicaklık, yağış, nem ve rüzgârdır.

Akdeniz bölgesinde rüzgâr genellikle kışın karadan denize, yazın ise denizden karaya doğru eser (Uslu 1974). Araştırma alanında rüzgârın en fazla Güneybatı yönünde ve aylara göre en hızlı rüzgâr $31,4 \mathrm{~m} / \mathrm{s}$ hızla Ekim ayında estiği görülmektedir (Anonymous, 2004). Bölgenin hâkim rüzgâr hızı ve yönü denize yakın uzanan vadilerde yayılan bitki birlikleri için çok önemlidir. Çünkü bu yönde şiddetli esen rüzgâr, vadilerin güneye bakan yamaçlarında hem evapotransprasyon yoluyla toprak suyunun hızla buharlaşmasına hem de bitkilerin transprasyon hızını artırarak su stresi yaşamalarına yol açmıştır. Bu nedenle gerek bitki birlikleri gerekse buradaki bitki türleri ve bunların fizyonomisi değişmektedir. $\mathrm{O}$ yüzden bu habitatlardaki bitkiler kısa boylu bodur kaldıkları gibi habitattaki genel örtüş oranları da büyük ölçüde zayıflamış ve eğimi fazla olan yerlerde toprak erozyonu hızlanmıştır.

Bölgenin yıllık yağış miktarı 895,2 mm'dir. Ancak, araştırma alanı bitki örtüsünün optimum gelişim gösterdiği dönem olan Mayıs, Haziran, Temmuz aylarında en düşük yağış miktarını almaktadır (Anonymous, 2004). Vejetasyonun canlı olduğu Nisan-Eylül ayları arasında hava neminin \% 75'i (Anonymous, 2004) geçmesi önemli bir etkidir. Çünkü yüksek nem, çok az yağış alan yaz kuraklığında bitkilerin güneşten etkilenme derecesini azaltmaktadır. Bu dönem aralığındaki sicaklık ve nemin optimum özelliği makilerde büyümenin sürekliliğini sağladığından dolayı ekosistemin tampon gücünü koruyacak prodüktiviteye imkan vermesidir.

Araştırma alanına özel ekolojik anlam kazandıran vadiler, Samandağ Meydan köyünden itibaren Kel Dağı'nın kuzeyindeki Gözlüce ve Aydınbahçe yerleşim birimlerine kadar uzanır. Vadilerin bitiş noktasında arazinin bakısı ve yüksekliğine göre de özellikle maki bitki türlerinin hâkimiyeti değişir. Vadilerin güneye bakan yamaçları ve dışında kalan alanlar \% 70-80 örtüşlü Quercus coccifera, Myrtus communis, Pistacia terebinthus, Cotinus coggygria, Genista acanthoclada, Cistus salviifolius ve $C$. creticus türlerinden ibarettir. Ancak vadiler arasındaki yamaçların zirvelerinden aşağıya inildikçe eğimin arttığı yamaçlarda bitki örtüsü daha sık ve iyi gelişmiştir. Özellikle kuzeye bakan $\%$ 50-75 eğimli sarp yamaçlarda yakıcı güneşin etkisi ve insan tahribi az olduğu için makiler çok iyi geliştiği gibi örtüş-bolluk durumları da artmıştır. Ayrıca bu durum vadinin açık tarafından gelen hızlı rüzgârların bitkilerde aşırı transprasyonu engellediği gibi fotosentezin hızını da yükselterek bitkilerin boyca uzamasını kolaylaştırmıştır. Arbutus andrachne ve Spartium junceum hâkim durumda olduğu bu yamaçlarda örtüş \%100 kadardır.

Günümüzde hızla artan insan nüfusu lüks yaşamı için doğal ortamları hızla kirletmektedir. Doğal ortamların bütünleyicisi ve iklime denge kazandıran bitki örtüsü, en fazla tahrip edilen varlıktır. İnsanlar, biyosferde işgal ettiği gerçek çevre olan akuatik ve karasal ekosistemlerin hemen tümünü kontrol etmeye başlamasından itibaren israfa dönüşen sömürücü baskıyla yok edici bir rolü üstlenmiştir. Fenik Yaylası ve çevresinin doğal bitki birlikleri üzerindeki insan kaynaklı olumsuz etkileri aşağıda verilmiştir:

Yapılaşma: Bölgenin Samandağ kesimindeki Meydan Kumsalının Sabra Burnu yönünden başlayarak Aydınbahçe ve Gözlüce yerleşim alanları arasında kalan bölümde hızla yapılaşma başlamıştır. Bu yapılaşma, bitki örtüsünün denizle buluştuğu ve mükemmel doğal güzelliklerin olduğu alanda yazlık konut ve çay bahçeleri şeklinde yapılaşma faaliyetleridir.

Bitki türlerinin sökülmesi ve aşırı kesimi: Bölgenin doğu ve batı tarafinın yerleşim alanlarına yakın olması, başta meşe ve sandal ağacı gibi büyük makilerin aşırı kesimi ve naklini kolaylaştırmıştır. Özellikle köylüler sonbaharda kışın 1sınma 
gereksinimini karşılamak, yazın da tandırda ekmek pişirmek için tüm odunsu bitkilerin büyük ve kalın dalların kesmektedir. Bu tahribat yer yer bitkilerin optimum gelişme gösterdiği ilkbahar döneminde de yapilarak yaz sicaklarında kuruduktan sonra sonbaharda katırlarla evlere indirilmektedir. Ayrıca, yöredeki bazı bitki türlerinin, özellikle defne ve bazı odunsu tıbbi bitkiler gibi türlerin, köklenerek sökülmesi de aynı tahribata neden olmakta ve bitki topluluklarının kompozizyonlarında değişme ve frekanslarında azalmaya neden olmaktadır. Sonuçta her iki tahribat faktörüyle açılan alanlarda erozyon başlamakta ve kırmızı topraklar denize sürüklenmektedir.

Otlatma: Fenik Yaylası'na son dönemde çiftlik ev ve ahır gibi çarpık yapılaşma yaparak yerleşen halkın geçim kaynağı tarım ve hayvancılıktır. Bölgede mera gibi alanların olmaması nedeniyle otlatma yeri olarak maki bitki örtüsü kullanılmaktadır. Başta karakeçi olmak üzere ilkbahardan itibaren bölgeye serbest birakılan hayvanlar odunsu bitkilerin yeni faaliyete geçen meristemlerini kopardıkları için bu bitkiler boyca uzama yerine sarmaşık gibi yerde sürünmeye başlamışlardır. Ayrıca otlatmanın ve örtüşün biraz daha az yoğun olduğu alanlarda da boyu kısa bodur kalmıştır.

Zirai alanların açılması: Kontrolsüz artan nüfusa yeterli besin sağlayabilmek için çalışma alanımızın eğimi az, kayalık kesimleri arasındaki hafif taşlı derin topraklı organik maddece zengin habitatlar tarım arazisine dönüştürülmektedir. Buradaki yoğun bitki örtüsü önce yakılarak terk edilmekte sonra da ertesi yılın baharında teraslama yöntemiyle

\section{LITERATÜR LISTESI}

Akman, Y. 1973a. Contribution a le etude de la des montagnes de I'amanus, I-III Comm. Fac. Sci. Univ. Ank. Seri C 17: 1-70.

Akman, Y. 1973b. Apercu preliminaire sur les conditions phytosocioloqiques de la chaine de L'Amanous dans la region du Hatay (I-II-II). Com De La Fac-Des sicid'Ank. Serie C, Tome 17.

Akman, Y. 1995. Türkiye Orman Vejetasyonu. Ankara Üniv. Fen. Fak. Botanik Anabilim Dalı, Ankara. tarla yapılmaktadır. Söz konusu tahribat doğal vejetasyonun ortadan kaldırılması şeklinde daha tehlikeli boyutta sürmektedir. Zamanla daha kolay anlaşılmakla birlikte insan etkisisonucu hızla tahrip olan doğal bitki birlikleri (vejetasyon) iklimde de aynı hızla değişime ve kararsızlığa neden olmaktadır. Bu durum günümüzde çok güncel bir konu olan küresel ısınma olayının gerçekte küresel biyolojik iklim değişiminin göstergesidir.

Fenik yaylası ve çevresinin bitki örtüsü Anadolu'ya özgü diğer bölgelerde olduğu gibi olağanüstü güzellikler içeren doğal zenginliktir. Doğal bitki örtüsü üzerindeki insan kaynaklı olumsuz etkiler, geri dönüşümsüz bir hal almadan acilen önlenmelidir. $\mathrm{Bu}$ nedenle öncelikle devletin yetkili kurumlarının bu araştırma sonuçlarını dikkate alarak yukarıda siralanan insan kaynaklı tahribatı engellemek ve doğal bitki örtüsünün korunması için acil olarak kontrollü uygulamaya geçmesi gerekmektedir. Aynı zamanda etkili ve sürekli koruma tedbirleri belirlenerek, eğitim çalışmalarıyla yerel halk bu konuda bilinçlendirilmelidir.

\section{TEŞEKKÜR}

Bu çalışma, "Fenik Yaylası ve Çevresinin (Yayladağ/ Hatay) Bitki Sosyolojisi ve Ekolojisi Yönünden Araştırılması" isimli yüksek lisans tezinden hazırlanmıştır. Desteklerinden dolayı Ege Tarımsal Araştırma Enstitüsü Müdürlügü̈’ne teşekkür ederim.

Akman, Y., M. Barbero, and P. Quézel. 1978. Contribution a L'etude de la vegetation forestiere d'Anatolie mediterraneenne. Phytocoenologia 5 (1): 1-79.

Akman, Y., M. Barbero, and P. Quézel. 1979a. Contribution a L'etude de la vegetation forestiere d'Anatolie mediterraneenne. Phytocoenologia 5 (2): 189-276.

Akman, Y., M. Barbero, and P. Quézel. 1979b. Contribution a L'etude de la vegetation forestiere d'Anatolie mediterraneenne. Phytocoenologia 5 (3): 277-346. 
Allison, L. E., and C.D. Noode. 1965. Carbonete (C.A.Biake, Editör) methods of soil analysis. Part. II Agronomy series, No:9 American Soc. Of Agro., Winciston, s. $1367-1368$.

Anonymous, 2004. Ekstrem sicaklık yağış değerleri, meteoroloji bülteni, Meteoroloji Gen. Müd. Yayınları, Ankara.

Atalay, İ. 1987. Türkiye Jeomorfolojisine Giriş. Ege Üniv. Edebiyat Fak. Yay. No:9, İzmir.

Billings, W.D., and H.A. Mooney. 1968. The Ecology of arctic and alpine plants. Biological Reviews, 43: 481529.

Bouyoucos, G.J. 1962. Hydrometer method improved for making particle size analysis of soils. Agronomy Journal 54:464-465.

Braun-Blanquet, J. 1932. Plant sociology (Translated by Fuller and Conrad). New York, London.

Braun-Blanquet, J. 1947. The vegetation cover in the Montpellier region and its relationship with soil. Sigma Communication (Support for Improvement of Govern- ance and management Programme). 94, Montpellier.

Bremner, J. M. 1965. Total Nitrogen. Chapter 83. pp. 1149 1178. In: A. G. Norman (Ed.) Methods of soil analysis. Part. II, Chemical and Microbiological Methods. Am. Soc. Agron. Inc. Madison, Winciston.

Byfield A. ve H. Çakan. 2005. Amanos Dağları. İstanbul: WWF Türkiye. 122 Önemli Bitki Alanları. 2005.

Çakan, H. 1997. Musa ve Kel Dağlarının (Hatay) bitki ekolojisi, Ç. Ü. Fen BilimleriEnstitüsü Doktora Tezi, Adana.

Davis, P.H. (1965-1985). Flora of Turkey and the East Aegean Islands, Vol: 1-9. Edinburgh University Pres, Edinburgh.

Davis, P.H., R.R. Mill, and K. Tan. 1988. Flora of Turkey and The East Aegean Islands (Supplement). Edinburgh University Press. Vol. 10, Edinburgh.

Demirsoy, A. 1996. Genel ve Türkiye Zoocoğrafyas1. Meteksan AŞ. Ankara.

Duman, H. ve Z. Aytaç. 1994. Ahır, Berit, Binboğa ve Öküzdağlar (Kahramanmaraş-Kayseri) Yüksek Dağ stebinin flora ve vejetasyonu, TBAG-940 Nolu Proje, Tübitak, Ankara.

Düzenli, A. 1976. Hasan Dağı'nın bitki ekolojisi ve bitki sosyolojisi yönünden araştırılması. Ormancılık Araştırma Enstitüsü Dergisi, 22: 2.

Ege, İ. 2014. Amik Ovası ve Yakın Çevresi'nin Jeomorfolojisi, Doğu Mat Grup Matbaacılık Ltd. Şti., ISBN: 978-60584765-0-9, s.25

Ekim, T. 2002. TÜRSAB Botanik Seminer Notları, İstanbul Üniversitesi Fen Fakültesi Botanik Anabilim Dalı. İstanbul.
Güner, A., N. Özhatay, T. Ekim, and H.K.C. Başer. 2000. Flora of Turkey and East Aegean Islands. Edinburgh University press. Supplement 2 Vol.11. $656 \mathrm{~s}$. Edinburgh.

Güner, A., S. Aslan, T. Ekim, M. Vural ve M.T. Babaç. 2012. Türkiye Bitkileri Listesi (Damarlı Bitkiler). Nezahat Gökyiğit Botanik Bahçesi ve Flora Araştırmaları Derneği Yayını. İstanbul.

Güzelmansur, A. ve Y. Lise. 2013. Amanos Dağları'nın biyoçeşitliliği. MKU Ziraat Fakültesi Dergisi 18 (2): 55-68, ISSN 1300-9362.

Karagöz, A., N. Zencirci, A. Tan, T. Taşkın, H. Köksel, M. Sürek, C. Toker ve K. Özbek. 2010. Bitki Genetik Kaynaklarının Korunması ve Kullanımı. Türkiye Ziraat Mühendisliği VII. Teknik Kongresi. 11-15 Ocak. Bildiriler Kitabi. s.: 155-177.

Kılınç, M., Kutbay, H. G. 2004. Bitki Ekolojisi. Palme Yayınc1lı. Ankara.

Ocakverdi, H. 1990. Karadağ'ın (Karaman) fitososyolojik ve fitoekolojik yöndena raştırılması. Selçuk Üniv. Araştırma Fonu Proje No: 88-002, Konya

Quézel, P., M. Barbéro, and Y. Akman. 1978. L'Interpretation phytosociologique des groupements forestiers dans le basin Mediterraneen Oriental. Documents Phytosociologiques 2: 329-352 (in French).

Quézel, P., M. Barbéro,and Y. Akman. 1980. Contribution a L'etude de la vegetation forestiere d'Anatolie septentrionale Phytocoenologia, 5(3/4): 365-519 Stuttgart-Lehren.

Quézel, P., M. Barbéro, and Y. Akman. 1992. Typification de syntaxa décrits en région méditerranéenne orientale. Ecologia Mediterranea 18: 81-87 (in French).

Richards, L, A. 1954. Diagnosis And İmpravenent Of Saline And Alkali Soils. Hand book 60. U.S. Goverment Printing Office Washington.

Seçmen, Ö., Y. Gemici, G.Görk, L. Berat, ve E. Leblebici. 2008. Tohumlu Bitkiler Sistematiği. Ege Üniversitesi Fen Fakültesi Kitapları Serisi No:116. İzmir.

Tamer, Y. 1974. Hatay- Yayladağı Bölgesi Fosfat ve Jeolojik Etüdü. Ankara.

Tan, A., T. Taşkın. 2001. Herbaryum Hazırlama Teknikleri. TAYEK/TYUAP. 4-6 Eylül 2001. 103: 1-6. Menemen İzmir.

Uslu, T. 1974. Mersin ile Silifke arası kumul ve maki vejetasyonunun bitki ekolojisi ve sosyolojisi yönünden araştırılması. Doktora tezi. Ankara Üniversitesi Fen Fakültesi. Ankara.

Uslu, T. 1977. Plant ecological and sociological research on the dune and maquis vegetation between Mersin and Silifke, Communications Com. De la Fac-Des Sci-d' Ank. Seric C2, Torne 21. 
Vural, M., H. Duman, A. Güner, A. A. Dönmez ve H. Şağban. 1994. The vegetatition of Köyceğiz-Dalyan (Muğla) special protected area. Tr. J. of Botany 19: 431-476.

Vural, M., Y. Akman, and P. Quézel. 1999. Contribution a l'etude de la vegetation forestiere du Taurus central: analyse phyto-ecologique d'un sud-nord, entre Silifke et Karaman. Fitosociologia 36 (1): 3-21, 1999.

Yılmaz, T. 1996. Akdeniz doğal bitki örtüsü. Çukurova Üniversitesi Yayınları No: 172. Adana.

Yılmaz, Y., O. Gürpınar, N. Yalçın, C. Yetiş, E. Yiğitbaş, Y. Günay, B. Sarıtaş. 1984. Amanos dağlarının jeolojisi. İstanbul Üniv. Mühendislik Fak. TPAO raporu no: 1920,.1-4. 591 syf. Ankara.

Yolcu, H. 2005. Kızıldağ (Hatay) vejetasyonunun araştırılması. Ç. Ü. Fen Bilimleri Enstitüsü Doktora Tezi. Adana.

Yurdakulol, E. A. 1973. Phytosociologique and ecological research on the vegetation of the pos forest (Adana distr. Karsant1) of the Anti-Taurus Mountain, Communications De La Faculte des Sciences De L’Universte, Seri C2, Supp1:1-50 Ankara.

Zohary, M. 1962. Plant Life of Palestine. The Ronald Press Co. New York.

Zohary, M. 1973. Geobotanical Foundations of The Middle East,Vol;1-2, Stuttgart. 